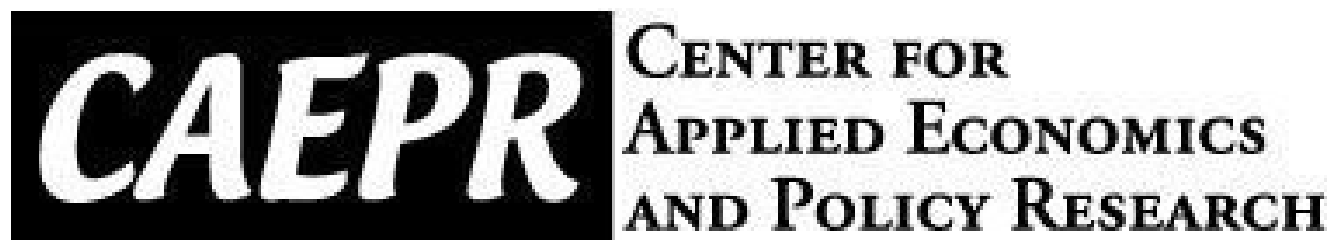

CAEPR Working Paper

\#2016-001

Foreign Asset Accumulation among Emerging Market Economies: a Case for Coordination

\author{
Hao Jin \\ Xiamen University \\ Hewei Shen \\ Indiana University \\ February 2016 \\ Revised \\ September 14, 2017
}

This paper can be downloaded without charge from the Social Science Research

Network electronic library at https://papers.ssrn.com/abstract_id=2995636

The Center for Applied Economics and Policy Research resides in the Department of Economics at Indiana University Bloomington. CAEPR can be found on the Internet at: http://www.indiana.edu/ caepr. CAEPR can be reached via email at caepr@indiana.edu or via phone at 812-855-4050.

(C)2017 by Hao lin and Hewei Shen. All rights reserved. Short sections of text, not to exceed two paragraphs, may be quoted without explicit permission provided that full credit, including (c) notice, is given to the source. 


\title{
Foreign Asset Accumulation among Emerging Market Economies: a Case for Coordination*
}

\author{
Hao Jin ${ }^{\dagger}$ \\ Xiamen University \\ Hewei Shen ${ }^{\ddagger}$ \\ Indiana University
}

\begin{abstract}
We develop a two-sector, core-periphery country general equilibrium framework with endogenous financial crises to study foreign asset accumulation coordination among emerging market economies. Consistent with the policy prescription in Bianchi (2011), we show that a national planner in each peripheral country prefers a higher asset position than the decentralized agents, but may not always improve welfare. A coordinator for all peripheral countries, who considers the effect of aggregate peripheral savings on the world interest rate, prefers a different asset position than the national planner. Our quantitative analysis shows that in the absence of coordination, the welfare gain from national regulation is negligible. In contrast, the coordinated level of net foreign assets is $53 \%$ of the uncoordinated level, and results in a sizable welfare gain.

Keywords: Foreign Asset Accumulation; World Interest Rate; Policy Coordination; Credit Constraints; Financial Crises.
\end{abstract}

JEL Classification: D62; E43; F32; F42; G01

\footnotetext{
*We thank the editor, Matthias Doepke, an anonymous associate editor and an anonymous referee for insightful comments. We are indebted to Yongquan Cao, Juan Carlos Hatchondo, Siming Liu, Amanda Michaud, Jaeger Nelson and Changhua Yu for many thoughtful discussions. We thank seminar and conference participants at Central University of Finance and Economics, Indiana University, Peking University, Shandong University, Xiamen University, 2015 and 2016 Fall Midwest Macroeconomics Meeting, 2017 Asian Meeting of the Econometrics Society, and 2017 China Meeting of the Econometrics Society. Jin acknowledges financial support from the Fundamental Research Funds for the Central Universities 20720171075. All errors are our own.

${ }^{\dagger}$ Corresponding author: Wang Yanan Institute for Studies in Economics and Department of International Economics and Trade, School of Economics, Xiamen University. Email: haojin.econ@gmail.com

$\ddagger$ Department of Economics, Indiana University, Bloomington. Email: heshen@indiana.edu
} 


\section{INTRODUCTION}

Financial distress in emerging market economies (EMEs) has stimulated many macroprudential policy proposals promoting the accumulation of foreign assets among those EMEs with less developed financial markets in an attempt to self-insure against financial crises. ${ }^{1}$ One of the theoretical arguments behind these policy prescriptions is that there exists a pecuinary externality as in Bianchi (2011). This pecuniary externality arises because private agents do not take into account the social benefit of holding liquidity in the presence of financial constraints, hence they "overborrow" during normal times. However, most existing studies of optimal macro-prudential policy are conducted in the context of a single EME and ignore the spillover effect from many EMEs to the global financial market. ${ }^{2}$ We revisit the merit of macro-prudential policy in the context of a multiple-country setup, which raises the issue of macro-prudential policy coordination among EMEs.

We argue in this paper that in addition to the precautionary saving motive at the national level, EMEs have incentives to coordinate on their net foreign asset (NFA) positions to strategically manipulate the world interest rate. While savings from individual EMEs are small, and thus have little influence on the prices of foreign assets, the aggregate savings from all EMEs are of considerable size and can affect international prices. Bernanke (2005) famously links the "global saving glut" to the low global interest rates observed in the 2000s. Follow-up empirical papers strongly support this hypothesis: the aggregate capital flows to international assets have a significant effect on the rate of returns of those assets. ${ }^{3}$ Therefore, the strategic world interest rate management motive interacts with country-level financial stability consideration, and calls for macro-prudential policy coordination among EMEs.

To formalize our analysis, we develop a two-sector, core-periphery country model to quantitatively evaluate the optimal foreign asset accumulation for EMEs in the presence of credit constraints. The periphery consists of a continuum of financially underdeveloped small open economies (SOEs), each facing a financial friction in which its borrowing is constrained by the market value of its collateral. The borrowing is denominated in the international unit of account, i.e. tradable goods. The collateral is in the form of current endowment income from both the tradable and nontradable sectors, as in Mendoza (2002) and Bianchi (2011). The core country is financially developed, and does not face any credit constraints. In our framework, two effects are overlooked when the decentralized agents in the peripheral countries make asset decisions: a pecuniary externality and a general equilibrium effect of asset decisions on the world interest rate. A pecuniary externality emerges as decentralized agents fail to internalize the effect of their asset decisions on the market value of their collateral. In contrast to the existing literature, our framework also features an endogenous world interest rate which

\footnotetext{
${ }^{1}$ See for example Mendoza (2002) and IMF (2010).

${ }^{2}$ Exceptions include Bengui (2013), Sergeyev (2014), Korinek (2016), and Kara (2016) where they explicitly consider global macro-prudential policy coordination in the face of systemic financial risk.

${ }^{3}$ For example, Warnock and Warnock (2009) finds international purchases of U.S. Treasuries significantly lowers U.S. long-term interest rates.
} 
is determined jointly by the peripheral and core countries. The decentralized agents in the peripheral countries take the world interest rate as given and fail to realize the market power they have in the world financial market as a large group of countries. Our key contribution is to combine these two considerations in a unified framework that is suitable for quantitative analysis.

In this paper, we compare three equilibrium allocations: (i) the decentralized equilibrium. (ii) the equilibrium of uncoordinated SOE planners who internalize the pecuniary externality and set macro-prudential regulations for individual peripheral countries, taking the world interest rate as given. (iii) the equilibrium achieved by a periphery coordinator who considers both pecuniary externality and the effect of peripheral countries' asset decisions on the world interest rate and coordinates macro-prudential policy for all peripheral countries. Our analytical result shows that the decentralized agents ignore the pecuniary externality and undervalue the liquidity of their asset holdings relative to the SOE planners, as highlighted in Bianchi (2011). The uncoordinated SOE planners thus encourage saving, or equivalently discourage borrowing, to reduce systemic risks. On the other hand, a periphery coordinator chooses a higher (lower) NFA position than the SOE planners when the peripheral countries borrow (save) in the international financial market, to obtain a more favorable world interest rate. Last but not least, both the pecuniary externality internalization and the world interest rate manipulation motive induce the periphery coordinator to borrow less than the decentralized agents. In contrast, these two considerations work in opposite directions when the peripheral countries are net creditors, and in this case the relative asset position between the periphery coordinator and decentralized agents is ambiguous.

After calibrating our model to a group of emerging Asian economies, our quantitative result suggests that the macroeconomic and welfare effects of macro-prudential policy coordination among peripheral countries are significant. The periphery coordinator chooses a much lower average NFA level than the other two equilibria: The average coordinated NFA level for each peripheral country is $53 \%$ of the uncoordinated level, and is $56 \%$ of the decentralized equilibrium level. Our welfare analysis shows that, in the absence of coordination, the welfare gain from pecuniary externality internalization is partially offset by unfavorable world interest rate variations, and national macro-prudential policy yields a negligible average welfare gain of $0.001 \%$ of permanent consumption in our baseline calibration. In contrast, the periphery coordinator who realizes both effects achieves an average welfare gain that is more than 20 times greater than the uncoordinated outcome. This result suggests that macroprudential policy proposals that fail to consider the general equilibrium effect on the world interest rate may be misguided. In addition, we also characterize a state-contingent tax instrument that can restore the coordinated allocations from the decentralized equilibrium.

Notice that our main objective is to quantitatively assess the internal and external macroeconomic and welfare impacts of macro-prudential policy coordination within a group of EMEs in the presence of both the pecuniary externality and the world interest rate manipu- 
lation motive. We are not pursuing a global welfare objective in this paper despite providing welfare implications of periphery coordination for the core country. In our model, a group of peripheral countries led by the periphery coordinator exerts their market power to manipulate the world interest rate while the core country acts passively. The coordination thus shifts surplus from the core to the periphery. As a result, the policy coordination we consider in this paper is desirable from the joint perspective of periphery countries, but not desirable from the core country's perspective.

The rest of the paper is structured as follows. We start with a discussion of the related literature in section 2 . In section 3 we introduce the model environment. In section 4 we formally define the three equilibria that we study and provide some theoretical results. In section 5 we apply the model to quantitatively assess the macroeconomic and welfare implications of foreign asset accumulation coordination. Finally, section 6 offers some concluding remarks.

\section{Related Literature}

This paper belongs to a recent literature that quantitatively evaluates the macroeconomic and welfare effects of systemic credit externalities, and the macro-prudential policy implications for SOEs. For example, some pioneering works include Bianchi (2011) and Bianchi and Mendoza (2013). ${ }^{1}$ In their works, SOEs are vulnerable to systemic risks because of credit constraints that give rise to pecuniary externalities. As a result, ex-ante restrictions on external liabilities can improve national welfare. Our framework extends their model to a global economy general equilibrium setup. This allows us to endogenize the world interest rate so that national macro-prudential policy spillovers to other countries through its impacts on the prices of internationally traded assets. We reconsider the merit of national macro-prudential policy in our framework, and show room for policy coordination among SOEs.

Our work is also related to another branch of literature that examines how large economies with global market power may manipulate intratermporal and/or intertemporal prices to extract economic rent. Some notable earlier contributions include Hamada (1966), Bardhan (1967), Hamada (1976), Harberger (1985). ${ }^{2}$ This concept was further developed in Rogoff and Obstfeld (1996), Costinot et al. (2014), and Korinek (2016). In our framework, many SOEs, by coordinating on their foreign asset accumulation, are capable of influencing intertemporal prices, i.e. the world interest rate, as a large economy. We complement the existing literature by incorporating financial instability into the analysis, and studying how financial stabilization and intertemporal price manipulation interact with each other and affect optimal macroprudential policy. Consistent with these papers, we also find that distorting intertemporal prices in the global economy has a beggar-thy-neighbor effect. Therefore, the policy coordination we consider in this paper is not globally Pareto efficient. The welfare of periphery

\footnotetext{
${ }^{1}$ For theoretical analysis, see Caballero and Krishnamurthy (2001), Caballero and Krishnamurthy (2003), Lorenzoni (2008), Farhi et al. (2009), Korinek (2010), and DáVila and Korinek (2017).

${ }^{2}$ See Cooper (1985) and Persson and Tabellini (1995) for reviews of this literature.
} 
countries is improved at the expense of the core country. ${ }^{1}$ While not examining global policy coordination, we quantitatively show the internal and external welfare effects of policy coordination among a subgroup of countries in the world.

It is also important to discuss how our work is related to the macro-prudential policy coordination literature. In a two-symmetric-country liquidity demand framework, Bengui (2013) shows how the pecuniary externality and the world interest rate manipulation motive interplay with each other, and calls for global macro-prudential policy coordination. In his paper, each country is large and has an incentive to shift surplus from foreign agents to domestic agents by influencing the world interest rate, and thus policy coordination among countries can improve global welfare. In fact, the national planner in his model corresponds to the periphery coordinator in our paper. However, we focus on evaluating macro-prudential policy proposals for individual open EMEs when they are "small". In our setup, even though regulations by individual EMEs do not affect other countries, the pooling of their behavior has global implications through its effects on the world interest rate. We find that uncoordinated national macro-prudential policies that fail to consider the aggregate effects on the world interest rate can be costly in terms of welfare.

In a core-periphery region framework, Sergeyev (2014) investigates the welfare implications of financial integration and financial regulation in the presence of bank funding risks. In his work, financial regulation in one country spills over to other countries because of changes in both the fire-sale discount and the world interest rate. National macro-prudential policy shifts surplus from abroad to home and generates Pareto inefficient outcomes relative to coordinated policy. We consider the same macro-prudential policy spillover effects through the world interest rate and yield qualitatively similar welfare results. Unlike his papers, our analysis is quantitative in nature and is able to provide both normative and positive implications.

Kara (2016) develops a multiple-country model that features fire-sale externalities across countries. National regulators fail to internalize the cross-country externalities and choose inefficiently low levels of macro-prudential regulation. However, in his model, countries do not trade assets with each other and thus do not have incentives to manipulate international prices during normal times. Instead, we consider a model with risk-sharing between core and peripheral countries so that the financial stabilization consideration interacts with the interest rate manipulation motive, which may result in a lower or higher level of national macro-prudential regulation.

\section{Model EnVironment}

Consider a world economy that consists of two categories of countries, core and periphery. There are two types of goods: tradable and nontradable, where the tradable good can

\footnotetext{
${ }^{1}$ Rabe (2016) employs a multi-country setting to quantify the welfare effects of a competitive depreciation through unilateral implementation of capital controls, and also finds a "beggar-thy-neighbor" effect. But unlike this paper, he does not consider systemic risks in his paper.
} 
be traded internationally and the nontradable good must be consumed domestically. The periphery is composed of a continuum of SOEs and the core is a single large country. We assume that periphery countries are completely identical in the sense that they share the same preferences, market structure, and endowment processes. Each periphery country is populated by an infinitely-lived representative agent who receives stochastic endowments in tradable goods and nontradable goods in each period of life. Since all the peripheral countries are homogeneous with no idiosyncratic uncertainty, international borrowing and lending only takes place between the core and periphery. Moreover, the peripheral countries are financially underdeveloped such that the borrowing contracts are not perfectly enforceable. As a result, they face a collateral constraint and can only borrow up to a certain fraction of the market value of their income in each period. In contrast, the core country is financially developed so that it does not face such a collateral constraint.

We introduce two sources of aggregate uncertainties into the peripheral countries, one in the income process and the other in the financial market. In order to simplify the analysis and ease the computational burden, we assume there is no uncertainty in the core country.

3.1 Peripheral COUNTRIES There is a continuum of identical peripheral countries indexed by $i \in[0,1]$. We use superscript $i$ to denote the variables associated with the representative agent in each peripheral country $i$.

The representative agent in peripheral country $i$ consumes a combination of tradable and nontradable goods and maximizes life-time utility:

$$
U_{t}^{i}=E_{0} \sum_{t=0}^{\infty} \beta^{t} \frac{c_{t}^{i^{1-\gamma}}}{1-\gamma}
$$

where $c_{t}^{i}=\left[\omega\left(c_{T, t}^{i}\right)^{-\eta}+(1-\omega)\left(c_{N, t}^{i}\right)^{-\eta}\right]^{-1 / \eta}$ is a composite good and is produced using CES combination technology from tradable and nontradable goods. We let $\gamma$ denote the relative risk aversion, $\eta$ and $\omega$ measure the elasticity of substitution between tradable and nontradable goods and agents' relative preference for tradable goods, respectively.

The representative agent in peripheral country $i$ receives stochastic tradable and nontradable endowments each period and can borrow/lend in the international financial market by trading a one-period, risk-free bond. The bond is denominated in tradable goods and pays a gross interest rate $R_{t}$. The representative agent's flow budget constraint is given by:

$$
c_{T, t}^{i}+p_{t}^{i} c_{N, t}^{i}+b_{t+1}^{i}=y_{T, t}^{i}+p_{t}^{i} y_{N, t}^{i}+R_{t} b_{t,}^{i} \quad \forall t
$$

where $b_{t}^{i}$ denotes the representative agent's bond position in time $t$ and a positive value of $b_{t}^{i}$ indicates net savings in the international financial market. The relative price of nontradable goods in terms of tradable goods is denoted as $p_{t}^{i}$.

We assume that the peripheral countries are financially underdeveloped and face a col- 
lateral constraint when borrowing in the international financial market. In particular, the specification of the collateral constraint follows Bianchi (2011):

$$
-b_{t+1}^{i} \leq \kappa_{t}^{i}\left(y_{T, t}^{i}+p_{t}^{i} y_{N, t}^{i}\right)
$$

where their borrowing capacities are limited to a fraction $\kappa_{t}^{i}$ of the market value of their current period income. $\kappa_{t}^{i}$ is stochastic and measures the tightness of this borrowing constraint in period $t$.

We assume that all the peripheral countries are identical in their endowment processes and financial market conditions, so they have the same realization of endowments $\left[y_{T}, y_{N}\right]$ and financial conditions $\kappa$. Therefore, all the peripheral countries are homogeneous and will make the same decisions on consumption and bond positions. For the rest of the paper, we drop the identifier superscript $i$ unless we want to discuss one peripheral country specifically.

3.2 CORE COUNTRY There is one core country populated by a continuum of overlapping generation agents who live for two periods and consume only tradable goods. ${ }^{1}$ All the agents who are born in the same period are identical so that there is a representative agent for each generation in the core country. We denote all core country variables with a superscript asterisk, while time script $(t)$ means the variables that are associated with the agents born in period $t$. The core country agents do not face any uncertainties in their endowment process and all the agents receive the same endowments in their two periods of life. The core country is financially developed so that its agents do not face any frictions when trading in the international financial market.

A representative core country agent who is born in period $t$ maximizes lifetime utility:

$$
U_{t}^{*}=\log \left(c_{T, t}^{*}(t)\right)+\beta^{*} \log \left(c_{T, t+1}^{*}(t)\right)
$$

subject to the flow budget constraints,

$$
\begin{aligned}
c_{T, t}^{*}(t)+b_{t+1}^{*}(t) & =y_{1}^{*} \\
c_{T, t+1}^{*}(t) & =y_{2}^{*}+R_{t+1} b_{t+1}^{*}(t)
\end{aligned}
$$

where $b_{t+1}^{*}(t)$ is the next period bond position chosen by the representative agent born in period $t . y_{1}^{*}$ and $y_{2}^{*}$ are the constant tradable endowments that core country agents receive in the first and second period of their lives.

3.3 DISCUSSION OF ASSUMPTIONS A few comments about the assumptions are given here. In the model, we assume that there is a continuum of idetical peripheral countries that share

\footnotetext{
${ }^{1}$ The assumption of only consuming tradable goods enables us to analytically characterize the relationship between bond positions and the world interest rate as in lemma 1. The numerical results will not change qualitatively if we assume that the core country agents also consume a combination of tradable and nontradable goods.
} 
the same income processes and financial conditions. This assumption is strong but it reflects some observed features of EMEs: many EMEs are geographically close, such as those in Southeastern Asia or Latin America, their business cycle fluctuations are highly synchronized and they often experience financial crises together, such as 1997 Asian financial crisis and the Latin America debt crisis in the 1980s. ${ }^{1}$

We also assume that the core country is populated by overlapping generations rather than infinitely lived agents for numerical tractability. Under this assumption, the future interest rates do not matter for the current core country agents and the world interest rate depends only on the current aggregate borrowing/savings of the peripheral countries. However, this assumption is not innocuous. Costinot et al. (2014) finds that an infinitely lived agent cares about the change of capital flows over time so that the interest rate depends on the entire path of capital flows in the future instead of just the current capital flow. By assuming overlapping generation agents in the core country, the intertemporal terms-of-trade effect is absent in our model, and the elasticity of the world interest rate is higher than the case with infinitely-lived agents. To obtain meaningful quantitative results, we adjust the size of the core country in our calibration to match the elasticity of the world interest rate found in empirical studies.

In our model, we assume there is only one asset traded internationally: a one-period non-state-contingent bond. Therefore, the bond position of the peripheral countries in our model should be interpreted as the net foreign asset position and cannot shed light on global portfolio allocations. Our goal in this paper is to revisit the macro-prudential policy proposals such as Bianchi (2011), Korinek (2010) and Korinek (2011) in which only the net asset position matters for financial stability.

\section{EQUILIBRIUM}

4.1 Optimality CONDitions The decentralized agents in the peripheral countries choose tradable consumption, nontradable consumption, and bond position to maximize utility (3.1) subject to the budget constraint (3.2) and the collateral constraint (3.3). The first order conditions with respect to tradable and nontradable consumption yield the relative price function of nontradable goods:

$$
p_{t}=\frac{1-\omega}{\omega}\left(\frac{c_{T, t}}{c_{N, t}}\right)^{1+\eta}
$$

Notice that the relative price of the nontradable good is a function of domestic consumption of tradable and nontradable goods. The first order condition with respect to bond holdings implies the intertemporal Euler equation:

$$
U_{T, t}=\beta E_{t} R_{t+1} U_{T, t+1}+\mu_{t}
$$

\footnotetext{
${ }^{1}$ Meller and Metiu (2017) finds that the international credit cycle synchronization has increased significantly since the 1970s.
} 
where $U_{T, t}=\omega c_{t}^{1-\gamma} c_{T, t}^{-\eta-1} /\left(\omega c_{T, t}^{-\eta}+(1-\omega) c_{N, t}^{-\eta}\right)$ is the first derivative of the utility function with respect to tradable consumption, and $\mu_{t}$ is the Lagrangian multiplier associated with the collateral constraint (3.3). When the borrowing constraint is slack, the Lagrange multiplier $\mu_{t}$ equals to zero. In this case, (4.2) collapses to a standard Euler equation that equalizes the marginal utility of current period consumption and the expected discounted value of marginal utility from next period consumption. However, when the constraint (3.3) binds, $\mu_{t}$ is strictly positive and creates a wedge between the current and next period's marginal utility.

In the core country, the Euler equation of the representative agent who is born in period $t$ is given by:

$$
\beta^{*} R_{t+1}\left[y_{1}^{*}-b_{t+1}^{*}(t)\right]=y_{2}^{*}+R_{t+1} b_{t+1}^{*}(t)
$$

By rearranging terms, the world interest rate in period $t+1$ can be explicitly expressed as a function of the core country agents' bond decision and endowments:

$$
R_{t+1}=\frac{y_{2}^{*}}{-\left(1+\beta^{*}\right) b_{t+1}^{*}(t)+\beta^{*} y_{1}^{*}}
$$

4.2 MARKET CLEARING In equilibrium, the bond market, tradable goods market, and nontradable goods market all clear. Notice that the bond is of zero net supply, so the bond market clearing condition at period $t$ is:

$$
b_{t+1}=\int_{0}^{1} b_{t+1}^{i} d i=-b_{t+1}^{*}(t)
$$

where $i$ is the peripheral country index. The nontradable goods market clears within each peripheral country $i$ :

$$
c_{N, t}^{i}=y_{N, t}^{i}, \forall i
$$

and the tradable goods market clearing condition is:

$$
\int_{0}^{1} c_{T, t}^{i} d i+c_{T, t}^{*}(t)+c_{T, t}^{*}(t-1)=\int_{0}^{1} y_{T, t}^{i} d i+y_{1}^{*}+y_{2}^{*}
$$

\subsection{EQUILIBRIUM DEFINITIONS}

4.3.1 Decentralized Agents' Problem We now formally define the decentralized equilibrium of our model. We denote the bond position for the representative agent in peripheral country $i$ by $b^{i}$, the national bond position for peripheral country $i$ by $B^{i}$ and the aggregate bond position for all peripheral countries by $\mathcal{B}$. We use $\Gamma^{i}(\cdot)$ to denote the representative agent's forecast of the national bond position in peripheral country $i$, and $\Lambda^{i}(\cdot)$ to denote the his forecast of the aggregate bond position of all peripheral countries. Therefore, the state variables for the representative agent's problem are the agent's bond position $b^{i}$, the national 
bond position $B^{i}$, aggregate bond position for all peripehral countries $\mathcal{B}$, and the income and financial condition realizations, $y=\left[y_{T}, y_{N}\right]$ and $\kappa .^{1}$ The representative agent uses equations (3.2), (4.1) and (4.2) to forecast the relative price of nontradable goods. We denote the price function of nontradable goods in peripheral country $i$ as $p^{i}\left(B^{i}, \mathcal{B}, y, \kappa\right)$. Combining the core country agent's optimality condition (4.4) with the bond market clearing condition (4.5), we can express the interest rate as a function of the aggregate bond position of all peripheral countries: $R(\mathcal{B})=y_{2}^{*} /\left[\left(1+\beta^{*}\right) \mathcal{B}+\beta^{*} y_{1}^{*}\right]$.

The recursive problem of the representative agent in peripheral country $i$ is given by:

$$
V^{i}\left(b^{i}, B^{i}, \mathcal{B}, y, \kappa\right)=\max _{b^{i^{\prime}}, c_{T}^{i}, c_{N}^{i}} u\left(c\left(c_{T}^{i}, c_{N}^{i}\right)\right)+\beta E\left(V^{i}\left(b^{i^{\prime}}, B^{i^{\prime}}, \mathcal{B}^{\prime}, y^{\prime}, \mathcal{\kappa}^{\prime}\right) \mid y, \kappa\right)
$$

subject to the budget and financial constraints:

$$
\begin{aligned}
c_{T}^{i}+p^{i}\left(B^{i}, \mathcal{B}, y, \kappa\right) c_{N}^{i}+b^{i^{\prime}} & =y_{T}+p^{i}\left(B^{i}, \mathcal{B}, y, \kappa\right) y_{N}+R(\mathcal{B}) b^{i} \\
-b^{i^{\prime}} & \leq \kappa\left(y_{T}+p^{i}\left(B^{i}, \mathcal{B}, y, \kappa\right) y_{N}\right) \\
B^{i^{\prime}} & =\Gamma^{i}\left(B^{i}, \mathcal{B}, y, \kappa\right) \\
\mathcal{B}^{\prime} & =\Lambda^{i}(\mathcal{B}, y, \kappa)
\end{aligned}
$$

where the next period variables are denoted with a prime superscript.

Definition 1. (Recursive Equilibrium for the Decentralized Agents)

A recursive equilibrium for the decentralized agents' problem in peripheral country $i$ is defined by a pricing function $p^{i}\left(B^{i}, \mathcal{B}, y, \kappa\right)$, interest rate function $R(\mathcal{B})$, a perceived law of motion for the national bond position, $\Gamma^{i}\left(B^{i}, \mathcal{B}, y, \kappa\right)$, a perceived law of motion for the aggregate bond position for all peripheral countries $\Lambda^{i}(\mathcal{B}, y, \kappa)$, the decentralized agents' decision rules $\left\{\hat{b}^{i}\left(b^{i}, B^{i}, \mathcal{B}, y, \kappa\right), \hat{c}_{T}^{i}\left(b^{i}, B^{i}, \mathcal{B}, y, \kappa\right), \hat{c}_{N}^{i}\left(b^{i}, B^{i}, \mathcal{B}, y, \kappa\right)\right\}$ with the associated decentralized agents' value function $V^{i}\left(b^{i}, B^{i}, \mathcal{B}, y, \kappa\right)$, and the core country agents' decision rules $\left\{b^{*}(\mathcal{B}, y, \kappa), c_{1}^{*}(\mathcal{B}, y, \kappa), c_{2}^{*}(\mathcal{B})\right\}$ such that :

1. $\left\{\hat{b}^{i}\left(b^{i}, B^{i}, \mathcal{B}, y, \kappa\right), \hat{c}_{T}^{i}\left(b^{i}, B^{i}, \mathcal{B}, y, \kappa\right), \hat{c}_{N}^{i}\left(b^{i}, B^{i}, \mathcal{B}, y, \kappa\right)\right\}$ solves the recursive optimization problem of the representative agent in peripheral country $i$, taken as given $p^{i}\left(B^{i}, \mathcal{B}, y, \kappa\right)$, $R(\mathcal{B}), \Gamma^{i}\left(B^{i}, \mathcal{B}, y, \kappa\right)$ and $\Lambda^{i}(\mathcal{B}, y, \kappa)$.

2. The perceived law of motions are consistent with the actual law of motions: $\Gamma^{i}\left(B^{i}, \mathcal{B}, y, \kappa\right)=$ $\hat{b}^{i}\left(B^{i}, B^{i}, \mathcal{B}, y, \kappa\right), \Lambda^{i}(\mathcal{B}, y, \kappa)=\hat{b}^{i}(\mathcal{B}, \mathcal{B}, \mathcal{B}, y, \kappa)$

3. $\left\{b^{*}(\mathcal{B}, y, \kappa), c_{1}^{*}(\mathcal{B}, y, \kappa), c_{2}^{*}(\mathcal{B})\right\}$ satisfies the core country representative agent's optimality condition (4.3) and solves the core country agents' problem, given world interest rate $R(\mathcal{B})$.

\footnotetext{
${ }^{1}$ The decentralized agents understand that the endowments and financial conditions are identical across peripheral countries, so that $y_{T}^{i}=y_{T}, y_{N}^{i}=y_{N}$, and $\kappa^{i}=\kappa$.
} 
4. Markets clear: $y_{N}=\hat{c}_{N}^{i}\left(b^{i}, B^{i}, \mathcal{B}, y, \kappa\right), \Lambda^{i}(\mathcal{B}, y, \kappa)+b^{*}(\mathcal{B}, y, \kappa)=0$, and $\int_{0}^{1} \hat{c}_{T}^{i}\left(b^{i}, B^{i}, \mathcal{B}, y, \kappa\right) d i+$ $c_{1}^{*}(\mathcal{B}, y, \kappa)+c_{2}^{*}(\mathcal{B})=y_{T}+y_{1}^{*}+y_{2}^{*}$.

\subsubsection{Small Open Economy Planners' Problem The relative price function (4.1) in-} dicates that the relative price of nontradable goods in peripheral countries is increasing with their national level of tradable consumption. However, the decentralized agents in the peripheral countries take the prices as given. In particular, they do not internalize the effects of their consumption decisions on the price of nontradable goods. This effect is the pecuniary externality that has been highlighted in the recent macro-prudential policy discussions, such as in Bianchi (2011), Korinek (2010) and Korinek (2011). It arises at the national level since the price of nontradable good in any peripheral countries only depends on the domestic tradable and nontradable consumption.

Consider that there is a SOE planner in each of the peripheral countries who internalizes the pecuniary externality. Since all the peripheral countries are identical and subject to the same income processes and financial conditions, there exists a representative SOE planner for all the peripheral countries. Following the definition of a constrained social planner in Bianchi (2011), we assume that the representative SOE planner makes consumption and bond decisions directly for the residents in the peripheral countries subject to the same collateral constraint but allows the goods and bond markets to clear competitively. In section 4.4 , we show that this assumption yields the same result as if the representative SOE planner (1) imposes a tax on the decentralized agents' bond position and rebates the proceeds back to decentralized agents in a lump sum fashion, and (2) lets the decentralized agents make decisions on their consumption and bond position and lets the interest rate and price of nontradable goods be determined competitively.

The SOE planner's problem is similar to the one of the decentralized agents' except that the SOE planner takes into account the pricing function of nontradable goods (4.1). For the SOE planner, the states are the national bond position $B$, peripheral country aggregate bond position $\mathcal{B}$, endowment realization $y$, and financial market condition $\kappa$. Let $\Lambda(\mathcal{B}, y, \kappa)$ denote the perceived law of motion for aggregate bond holdings of all peripheral countries. After imposing market clearing conditions, we can write the SOE planner's problem as:

$$
V(B, \mathcal{B}, y, \kappa)=\max _{B^{\prime}, c_{T}} u\left(c\left(c_{T}, y_{N}\right)\right)+\beta E\left(V\left(B^{\prime}, \mathcal{B}^{\prime}, y^{\prime}, \kappa^{\prime}\right) \mid y, \kappa\right)
$$

subject to the resource and financial constraints:

$$
\begin{aligned}
c_{T}+B^{\prime} & =y_{T}+R(\mathcal{B}) B \\
-B^{\prime} & \leq \kappa\left(y_{T}+\frac{1-\omega}{\omega}\left(\frac{c_{T}}{y_{N}}\right)^{1+\eta} y_{N}\right) \\
\mathcal{B}^{\prime} & =\Lambda(\mathcal{B}, y, \kappa)
\end{aligned}
$$




\section{Definition 2. (Recursive Equilibrium for the Representative SOE Planner)}

The recursive equilibrium for the representative SOE planner's problem is defined by an interest rate function $R(\mathcal{B})$, the perceived law of motion of aggregate asset holdings for all peripheral countries $\Lambda(\mathcal{B}, y, \kappa)$, the decision rules $\left\{\tilde{B}(B, \mathcal{B}, y, \kappa), \tilde{c}_{T}(B, \mathcal{B}, y, \kappa)\right\}$ with associated value function $V(B, \mathcal{B}, y, \kappa)$, and the core country agents' decision rules $\left\{b^{*}(\mathcal{B}, y, \kappa)\right.$, $\left.c_{1}^{*}(\mathcal{B}, y, \kappa), c_{2}^{*}(\mathcal{B})\right\}$, such that:

1. $\left\{\tilde{B}(B, \mathcal{B}, y, \kappa), \tilde{c}_{T}(B, \mathcal{B}, y, \kappa)\right\}$ solves the recursive optimization problem of the representative SOE planner, given $R(\mathcal{B})$ and $\Lambda(\mathcal{B}, y, \kappa)$.

2. The perceived law of motion is consistent with the actual law of motion:

$$
\Lambda(\mathcal{B}, y, \kappa)=\tilde{B}(\mathcal{B}, \mathcal{B}, y, \kappa)
$$

3. $\left\{b^{*}(\mathcal{B}, y, \kappa), c_{1}^{*}(\mathcal{B}, y, \kappa), c_{2}^{*}(\mathcal{B})\right\}$ satisfies the core country agents' optimality condition (4.3) and solves the core country agents' problem, given interest rate $R(\mathcal{B})$.

4. Markets clear: $\Lambda(\mathcal{B}, y, \kappa)+b^{*}(\mathcal{B}, y, \kappa)=0$, and $\tilde{c}_{T}(B, \mathcal{B}, y, \kappa)+c_{1}^{*}(\mathcal{B}, y, \kappa)+c_{2}^{*}(\mathcal{B})=$ $y_{T}+y_{1}^{*}+y_{2}^{*}$.

The first order conditions of the SOE planner's problem are:

$$
\begin{gathered}
\lambda_{t}^{\text {soep }}=U_{T, t}^{\text {soep }}+\mu_{t}^{\text {soep }} \Psi_{t}^{\text {soep }} \\
\lambda_{t}^{\text {soep }}=\beta E_{t} R_{t+1} \lambda_{t+1}^{\text {soep }}+\mu_{t}^{\text {soep }}
\end{gathered}
$$

where superscript soep denotes the SOE planner's variables. $\lambda_{t}^{\text {soep }}$ and $\mu_{t}^{\text {soep }}$ are the Lagrangian multipliers attached to the budget constraint (4.14) and collateral constraint (4.15) respectively, and $\Psi_{t}^{\text {soep }}=\kappa_{t} p_{t}(1+\eta)\left(c_{N, t} / c_{T, t}\right)$. Combining the first order conditions, we obtain the Euler equation for the representative SOE planner:

$$
U_{T, t}^{\text {soep }}=\beta E_{t} R_{t+1}\left[U_{T, t+1}^{\text {soep }}+\mu_{t+1}^{\text {soep }} \Psi_{t+1}^{\text {soep }}\right]+\mu_{t}^{\text {soep }}\left(1-\Psi_{t}^{\text {soep }}\right)
$$

A comparison between the Euler equations (4.2) and (4.19) shows how the valuations of bond holdings from the decentralized agents and the SOE planners differ and we summarize the findings in Proposition 1.

Proposition 1. When the borrowing constraint is not binding and there is a positive probability that the collateral constraint will bind in the next period, the small open economy planners value bond holdings in the next period more than the decentralized agents.

Proof. See Appendix A.1

The intuition behind this proposition is that the SOE planners realize that an additional unit of liquidity carried over to the next period reduces the peripheral country agents' need 
for borrowing in the next period and thus reduces the probability and severity of a binding collateral constraint.

Notice that the representative SOE planner's problem in our model is the same as the constrained social planner's problem in Bianchi (2011). However, the model in Bianchi (2011) features a constant world interest rate, whereas we generalize his framework by endogenizing the world interest rate. In our numerical results, we show that the SOE planner's problem in our paper results in the same asset allocation implication, qualitatively, as in Bianchi (2011): the SOE planners choose higher bond positions than the decentralized agents, even when the peripheral countries are net savers in the international financial market and the bond position is very far from the binding area. However, the welfare implication is different. In our setup, the SOE planners' allocations do not always improve national welfare due to the possibility of unfavorable world interest rate movements.

Schmitt-Grohé and Uribe (2016) shows that multiple equilibria may exist in the Bianchi (2011) type of small open economy model in which the market values of tradable and nontradable endowments serve as collateral. Specifically, in addition to the "overborrowing" equilibrium, this type of model may yield an "underborrowing" equilibrium such that the private agents build up excessive precautionary savings to self-insure against financial crises when they are pessimistic and the financial crises become self-fulfilling. Jeanne and Korinek (2010) heuristically investigates the existence of multiple equilibria in this type of model and finds that a low value of the collateral tightness parameter will help prevent multiple equilibria. Although we cannot completely rule out the possibility of having multiple equilibra in our model, we conduct robustness checks when solving the model by starting from different initial guesses. We always find that the decentralized equilibrium features "overborrowing" as in Bianchi (2011) under the baseline calibration.

\subsubsection{PERIPHERY COORDINATOR'S PROBLEM The SOE planners take the world interest rate} as given because each peripheral country is infinitely small and its planner does not consider the effect of the aggregate savings/borrowing decisions of all the peripheral countries on the world interest rate. In this section, we first characterize the relationship between the world interest rate and aggregate bond holdings by peripheral countries in lemma 1 , and then show a coordinator for all the peripheral countries will value bond holdings differently compared to individual SOE planners.

Lemma 1. The world interest rate $R_{t}$ is monotonically decreasing with the peripheral countries' aggregate bond position.

Proof. See Appendix A.2

This lemma highlights an important feature of our model: the world interest rate is endogenous and depends on the aggregate bond position. As the peripheral countries increase their bond positions (e.g. save more in the international financial market), the core country 
agents are willing to borrow only when the gross interest rate is lowered. Similarly, the core country is willing to lend more only when the gross interest rate rises.

Let us consider a periphery coordinator who directly chooses the bond position for all the peripheral countries subject to the same borrowing constraint, but allows the goods and bond markets to be cleared competitively. Crucially, the periphery coordinator understands the impact of aggregate bond positions on the world interest rate when making borrowing and savings decisions.

We now define the recursive equilibrium for the periphery coordinator's problem. The periphery coordinator takes into account the pricing functions of both the world interest rate (4.4) and nontradable goods (4.1). The state variables for the periphery coordinator are the aggregate bond position $\mathcal{B}$, the endowment process $y$, and financial market condition $\kappa$. The recursive problem for the periphery coordinator is written as:

$$
V(\mathcal{B}, y, \kappa)=\max _{\mathcal{B}^{\prime}, c_{T}} u\left(c\left(c_{T}, y_{N}\right)\right)+\beta E\left(V\left(\mathcal{B}^{\prime}, y^{\prime}, \kappa^{\prime}\right) \mid y, \kappa\right)
$$

subject to the resource and financial constraints:

$$
\begin{aligned}
c_{T}+\mathcal{B}^{\prime} & =y_{T}+R(\mathcal{B}) \mathcal{B} \\
-\mathcal{B}^{\prime} & \leq \kappa\left(y_{T}+\frac{1-\omega}{\omega}\left(\frac{c_{T}}{y_{N}}\right)^{1+\eta} y_{N}\right)
\end{aligned}
$$

Definition 3. (Recursive Equilibrium for the Periphery Coordinator)

The recursive equilibrium for the periphery coordinator's problem is defined by an interest rate function $R(\mathcal{B})$, the periphery coordinator's decision rules $\left\{\bar{B}(\mathcal{B}, y, \kappa), \bar{c}_{T}(\mathcal{B}, y, \kappa)\right\}$ with associated value function $V(\mathcal{B}, y, \kappa)$, and the core country agents' decision rules $\left\{b^{*}(\mathcal{B}, y, \kappa)\right.$, $\left.c_{1}^{*}(\mathcal{B}, y, \kappa), c_{2}^{*}(\mathcal{B})\right\}$, such that:

1. $\left\{\bar{B}(\mathcal{B}, y, \kappa), \bar{c}_{T}(\mathcal{B}, y, \kappa)\right\}$ solves the recursive optimization problem of the periphery coordinator.

2. $\left\{b^{*}(\mathcal{B}, y, \kappa), c_{1}^{*}(\mathcal{B}, y, \kappa), c_{2}^{*}(\mathcal{B})\right\}$ satisfies the core country's optimality condition (4.3) and solves core country agents' problem, given interest rate $R(\mathcal{B})$.

3. Markets clear: $\bar{B}(\mathcal{B}, y, \kappa)+b^{*}(\mathcal{B}, y, \kappa)=0, \bar{c}_{T}(\mathcal{B}, y, \kappa)+c_{1}^{*}(\mathcal{B}, y, \kappa)+c_{2}^{*}(\mathcal{B})=y_{T}+y_{1}^{*}+$ $y_{2}^{*}$.

In the equilibrium definitions, we use $b, B$ and $\mathcal{B}$ to denote the bond position of a representative agent in one of the peripheral countries, the national bond position of one peripheral country, and the aggregate bond position for all peripheral countries, respectively. However, in equilibrium, these bond positions are the same since the peripheral countries are identical and in unit measure. Therefore, we use $b$ to denote the aggregate bond position for all peripheral countries for the rest of the paper. 
Combining optimality conditions to get the periphery coordinator's Euler equation:

$$
U_{T, t}^{p c}=\beta E_{t} R_{t+1}\left[U_{T, t+1}^{p c}+\mu_{t+1}^{p c} \Psi_{t+1}^{p c}\right]+\mu_{t}^{p c}\left(1-\Psi_{t}^{p c}\right)+\beta E_{t}\left[U_{T, t+1}^{p c}+\mu_{t+1}^{p c} \Psi_{t+1}^{p c}\right] b_{t+1} \frac{\partial R_{t+1}}{\partial b_{t+1}}
$$

where the superscript $p c$ denotes the variables associated with the periphery coordinator's problem.

Notice that the last term in the periphery coordinator's Euler equation (4.23) drives a wedge between the marginal cost and marginal benefit of one additional unit of bond holdings relative to the SOE planner's Euler equation (4.19). This additional term captures the periphery coordinator's incentive to strategically manage the world interest rate. Intuitively, this interest rate consideration is more important as the net financial position becomes larger. As a result, the periphery coordinator has stronger motive to manipulate the interest rate when the bond decision is further away from zero, which is formalized in the following lemma.

Lemma 2. Given the periphery coordinator's bond choice is within a numerically relevant range, $b_{t+1} \in\left(-\beta^{*} y_{1}^{*} /\left(1+\beta^{*}\right), \beta^{*} y_{1}^{*} /\left(1+\beta^{*}\right)\right)$,

i. when the peripheral countries are saving in the international financial market $\left(b_{t+1}>0\right)$, the coordinator's incentive to strategically manipulate the world interest rate becomes stronger as the saving amount increases.

ii. when the peripheral countries are borrowing in the international financial market $\left(b_{t+1}<0\right)$, the incentive becomes stronger as the borrowing amount increases.

Proof. See Appendix A.3

We now compare the valuation of bond holdings by the periphery coordinator to the valuations in the other two equilibria in the following proposition.

Proposition 2. When the borrowing constraint is not binding, the periphery coordinator

i. values bond holdings in the next period less than the SOE planners when the peripheral countries are saving, and values bond holdings in the next period more than the SOE planners when they are borrowing.

ii. may value bond holdings in the next period more or less than the decentralized agents when the peripheral countries are saving, and values bond holdings in the next period more than the decentralized agents when they are borrowing.

Proof. See Appendix A.4

Because more savings in the international financial market will lower the rate of return on bonds, the periphery coordinator values bond holdings carried over to the next period 
less than the SOE planners when the peripheral countries are saving. On the other hand, the periphery coordinator values bond holdings in the next period more when the peripheral countries are borrowing, since less debt reduces the interest costs on borrowing.

When comparing the valuation between the periphery coordinator and the decentralized agents, the periphery coordinator considers both the pecuniary externality internalization and world interest rate manipulation while the decentralized agents ignore both. When the peripheral countries are borrowing, both considerations work in the same direction, and lead to a higher valuation of next period bond holdings. On the contrary, when the peripheral countries are saving, the pecuniary externality induces the periphery coordinator to value next period bond holdings more, but the strategic world interest rate manipulation motive suggests a lower bond position. As a result, the overall effect of theses two competing forces is ambiguous.

4.4 DeCENTRALIZATION In this section we investigate the use of policy instruments to implement the allocations of the SOE planners and the periphery coordinator in the decentralized equilibrium. Specifically, we show that the allocations chosen by the SOE planners and the periphery coordinator can be restored by imposing a tax on the decentralized agents' bond decisions.

Let $\tau_{t}$ be a tax imposed on the decentralized agents' bond position $b_{t+1}$ and the tax revenue is rebated back to the agents in a lump-sum fashion. The decentralized agents' Euler equation is now:

$$
U_{T, t}^{d e}=\beta E_{t} R_{t+1} U_{T, t+1}^{d e}\left(1+\tau_{t}\right)+\mu_{t}^{d e} .
$$

Proposition 3. The SOE planners' and the periphery coordinator's allocations can be implemented with a state-contingent tax on bond decisions, with tax revenue rebated as a lump-sum transfer.

Proof. See Appendix A.5

The state-contingent taxes that can restore the SOE planners' and the periphery coordinator's allocations are given by:

$$
\tau_{t}^{\text {soep }}=E_{t} \mu_{t+1}^{\text {soep }} \Psi_{t+1}^{\text {soep }} / E_{t} U_{T, t+1}^{\text {soep }}-\left(\mu_{t}^{\text {soep }} \Psi_{t}^{\text {soep }}\right) /\left(\beta E_{t} R_{t+1} U_{T, t+1}^{\text {soep }}\right)
$$

and

$$
\begin{aligned}
\tau_{t}^{p c} & =E_{t} \mu_{t+1}^{p c} \Psi_{t+1}^{p c} / E_{t} U_{T, t+1}^{p c}-\left(\mu_{t}^{p c} \Psi_{t}^{p c}\right) /\left(\beta E_{t} R_{t+1} U_{T, t+1}^{p c}\right) \\
& +E_{t}\left[U_{T, t+1}^{p c}+\mu_{t+1}^{p c} \Psi_{t+1}^{p c}\right] b_{t+1} \frac{\partial R_{t+1}}{\partial b_{t+1}} /\left(E_{t} R_{t+1} U_{T, t+1}^{p c}\right)
\end{aligned}
$$

The tax rate $\tau_{t}^{\text {soep }}$ represents the wedge between private and national valuation of bond holdings, and is exactly the same as the one that restores the national constrained-efficient allocations in Bianchi (2011). In contrast, the periphery coordinator sets the optimal tax to 
$\tau_{t}^{p c}$, which differs from the $\tau_{t}^{\text {soep }}$ by an additional term. The extra term captures the consideration of strategic world interest rate manipulation. When the peripheral countries are saving $\left(b_{t+1}>0\right)$, the last term in (4.26) is negative so that the coordinator subsidizes less on savings relative to the SOE planners in order to discourage savings and gain a higher rate of return. On the other hand, when the peripheral countries are borrowing $\left(b_{t+1}<0\right)$, the last term is positive so that the coordinator taxes borrowing more to induce less borrowing and thus reduce the borrowing costs.

\section{NUMERICAL ANALYSIS}

In this section, we describe the calibration and discuss the quantitative implications of our model. We solve for the decentralized equilibrium, the SOE planners' equilibrium, and the periphery coordinator's equilibrium numerically using global nonlinear methods (described in detail in Appendix B).

5.1 CALibration We calibrate our model using annual data of six Asian economies: Indonesia, Malaysia, Philippines, Thailand, Vietnam, and Republic of Korea from 1970 to 2012. We pick these economies because each of them is relatively small in size, has weak financial systems, and synchronizes business and credit cycles with each other. These characteristics are consistent with the underlying assumptions of the peripheral countries in our model. ${ }^{1}$

The calibrated parameter values are listed in table 1. Specifically, we set the risk aversion parameter of the periphery countries to $\gamma=2$. We fix the discount factors to $\beta=0.95$ and $\beta^{*}=0.95$ which imply a $5 \%$ annual risk-free interest rate in the steady state. The tradable goods preference parameter, $\omega=0.40$, is calibrated to match the average tradable output share of total output in the data. We follow Bianchi (2011) and set the elasticity of substitution between tradable and nontradable goods $1 /(1+\eta)$ to 0.83 . This number is a conservative value within the range of the empirical estimates of the elasticity of substitution. ${ }^{2}$

We assume the peripheral countries' endowments follow a bivariate autoregressive process,

$$
\log y_{t}=\rho \log y_{t-1}+\varepsilon_{t}
$$

where $y_{t}=\left[y_{t}^{T}, y_{t}^{N}\right]^{\prime}$ and $\varepsilon_{t}=\left[\varepsilon_{t}^{T}, \varepsilon_{t}^{N}\right]^{\prime} . \rho$ is a $2 \times 2$ matrix of autoregressive coefficients and

\footnotetext{
${ }^{1}$ Note that these sample countries all have positive NFA positions. In our model, positive NFA positions imply that the general equilibrium effect of higher aggregate savings resulting from macro-prudential policy in all peripheral countries will drive down the world interest rate, so that the welfare gain resulting from financial stability is partially offset by unfavorable variations in the world interest rate, as illustrated in section 5.4. On the other hand, if we calibrate our model to countries with negative NFA positions, the general equilibrium effect of lower aggregate borrowing resulting from national regulations will reduce the borrowing cost. This favorable world interest rate movement further improves the welfare gain of national macro-prudential policy beyond increased financial stability. As a result, the positive NFA case generates a more striking trade-off between the pecuniary externality and the strategic interest rate manipulation for national macro-prudential policy, and that is what we would like to quantify in this paper.

${ }^{2}$ The range of estimates for the elasticity of substirution is between 0.4 and 0.83 . Please see Stockman and Tesar (1990), Gonzalez-Rozada and Neumeyer (2003) and Mendoza (2005) for reference.
} 
Table 1: Parameters: Annual

\begin{tabular}{|c|c|c|}
\hline Statistic & Parameter Value & Source/Target \\
\hline \multicolumn{3}{|l|}{ Peripheral Countries } \\
\hline Discount Factor & $\beta=0.95$ & Standard Value \\
\hline Risk Aversion & $\gamma=2$ & Standard Value \\
\hline Preference for Tradable Goods & $\omega=0.40$ & Share of Tradable Output $=40 \%$ \\
\hline Elasticity of Substitution & $1 /(1+\eta)=0.83$ & Bianchi (2011) \\
\hline Income Process & See Text & Selected Group of Economies \\
\hline Collateral Coefficient (high) & $\kappa_{h}=0.35$ & Average NFA/Tradable GDP $=0.28$ \\
\hline Collateral Coefficient (low) & $\kappa_{l}=0.25$ & Average NFA/Tradable GDP $=0.28$ \\
\hline Collateral Coefficient Transition Prob. & $P_{h h}=0.9$ & Bianchi and Mendoza (2013) \\
\hline Collateral Coefficient Transition Prob. & $P_{l l}=0$ & Bianchi and Mendoza (2013) \\
\hline \multicolumn{3}{|l|}{ Core Country } \\
\hline Discount Factor & $\beta^{*}=0.95$ & Standard Value \\
\hline Endowment in 1st period of life & $y_{1}^{*}=140$ & World Interest Rate Elasticity \\
\hline Endowment in 2 nd period of life & $y_{2}^{*}=140$ & World Interest Rate Elasticity \\
\hline
\end{tabular}

$\varepsilon_{t}$ is normally distributed with zero mean and a variance-covariance matrix $\Omega$. We estimate $\rho$ and $\Omega$ from the HP-filtered tradable and nontradable output data obtained from the UN National Accounts Main Aggregates Database. For the classification of tradable sectors and nontradable sectors in the data, we classify the manufacturing sector and agricultural sector as tradable sectors and all the rest as nontradable sectors. Below we show the estimated autoregressive coefficients and the variance-covariance matrix.

$$
\rho=\left[\begin{array}{cc}
0.7481 & -0.1775 \\
0.4223 & 0.2815
\end{array}\right], \quad \Omega=\left[\begin{array}{cc}
0.0082086 & 0.00780367 \\
0.00780367 & 0.00812038
\end{array}\right]
$$

We follow Jermann and Quadrini (2012) and Bianchi and Mendoza (2013) to allow the collateral requirements to be time-varying. In particular, we assume that the financial market tightness parameter, $\kappa$, is stochastic. To simplify our analysis, we only consider two levels of $\kappa$ : high $\left(\kappa_{h}\right)$ and low $\left(\kappa_{l}\right)$ and it follows a Markov process. The values of $\kappa_{h}$ and $\kappa_{l}$ are calibrated to match the average NFA over tradable output ratio observed in the data. The NFA data is obtained from the World Bank's World Development Indicators. Following Bianchi and Mendoza (2013), we set $P_{h h}=0.9$ and $P_{l l}=0$, which means that the financial condition tightens every 10 years and remains tight for one year. ${ }^{1}$

The endowments of the core country agents $y_{1}^{*}$ and $y_{2}^{*}$ are both set to be 140 to match the elasticity of the world interest rate to capital flows. This means that the size of the core country is 140 times the peripheral countries' tradable output. This number is large since we assume that the core country is populated by overlapping generation agents rather than

\footnotetext{
${ }^{1}$ Bianchi and Mendoza (2013) calibrates these two parameters to match the frequency of financial crises and the duration of crises in the data. We do not calibrate these two parameters because we find the crisis probability is insensitive to the transition probability in our calibration. We experiment with different $P_{h h}$ between 0.5 and 0.9 , and the crisis probability only varies between $0.39 \%$ and $0.45 \%$.
} 
infinitely lived agents. As a result, only the current interest rate matters for the core country agents so that they are more sensitive to interest rate changes than infinitely lived agents.

5.2 EMPIRICAL PERFORMANCE Now we assess the empirical performance of our model by comparing the model-based moments to the data moments. The model moments are from the decentralized equilibrium. All the moments we compared are for the peripheral countries.

Table 2: First and Second Moments of Data and Decentralized Equilibrium

\begin{tabular}{llcc}
\hline \hline Moments & Description & Data & $\begin{array}{c}\text { Decentralized } \\
\text { Equilibrium }\end{array}$ \\
\hline$E\left(b / y_{T}\right)$ & Average NFA/Tradable GDP ratio & 0.28 & 0.28 \\
$\sigma(c) / \sigma(y)$ & Std Dev of Consumption relative to GDP & 1.15 & 1.09 \\
$\sigma(c a / y) / \sigma(y)$ & Std Dev of Current Account relative to GDP & 0.31 & 0.27 \\
$\rho(c, y)$ & Consumption Correlation with GDP & 0.99 & 0.76 \\
$\rho(c a / y, y)$ & Current Account/GDP Correlation with GDP & -0.51 & 0.38 \\
\hline
\end{tabular}

${ }^{a}$ Consumption is calculated as $c=y-c a$. Current account balance data is obtained from the IMF's WEO database.

$\mathrm{b}$ The GDP, $y$, is in units of tradables and calculated as the sum of tradable and nontradable output $y=y_{T}+p y_{N}$.

${ }^{c}$ We take log of all the data and HP-filter them with the exception of the current account balance.

From table 2, we can see the model moments match the data moments relatively well. First, the average ratio of NFA over tradable output in our model and the data are both $28 \%$. Second, our model successfully generates a higher volatility of consumption relative to the GDP. Also, the model moments match the correlation between consumption and GDP in the data. The relative volatility of current account to GDP slightly undershoots in our model and is 0.27 compared to 0.31 in the data. Our model fails to produce a countercyclical current account balance to output ratio because the peripheral countries are net savers on average in our model and do not experience sudden reversals in capital flows very often.

Our model generates an empirically plausible world interest rate schedule against capital flows. In figure 1 we produce a scatter plot to illustrate the relationship between capital flows and the world interest rate movements by using the decentralized agents' decision rules. As shown in the figure, the variations of the world interest rate and capital inflows to the core country are negatively correlated, which is consistent with lemma 1 . When the peripheral countries decide to accumulate more NFAs (i.e. positive capital flow into the core country), the world interest rate falls.

To quantitatively evaluate the elasticity of the world interest rate to capital flows, we regress the change of the world interest rate against the capital flows to get:

$$
\begin{aligned}
& \text { change of equilibrium interest rate }=-7.67 \times 10^{-5} \\
& \qquad-0.014 * \text { capital flow into the core country }+ \text { error term }
\end{aligned}
$$

The regression result suggests that the world interest rate falls by 45 basis points when the 


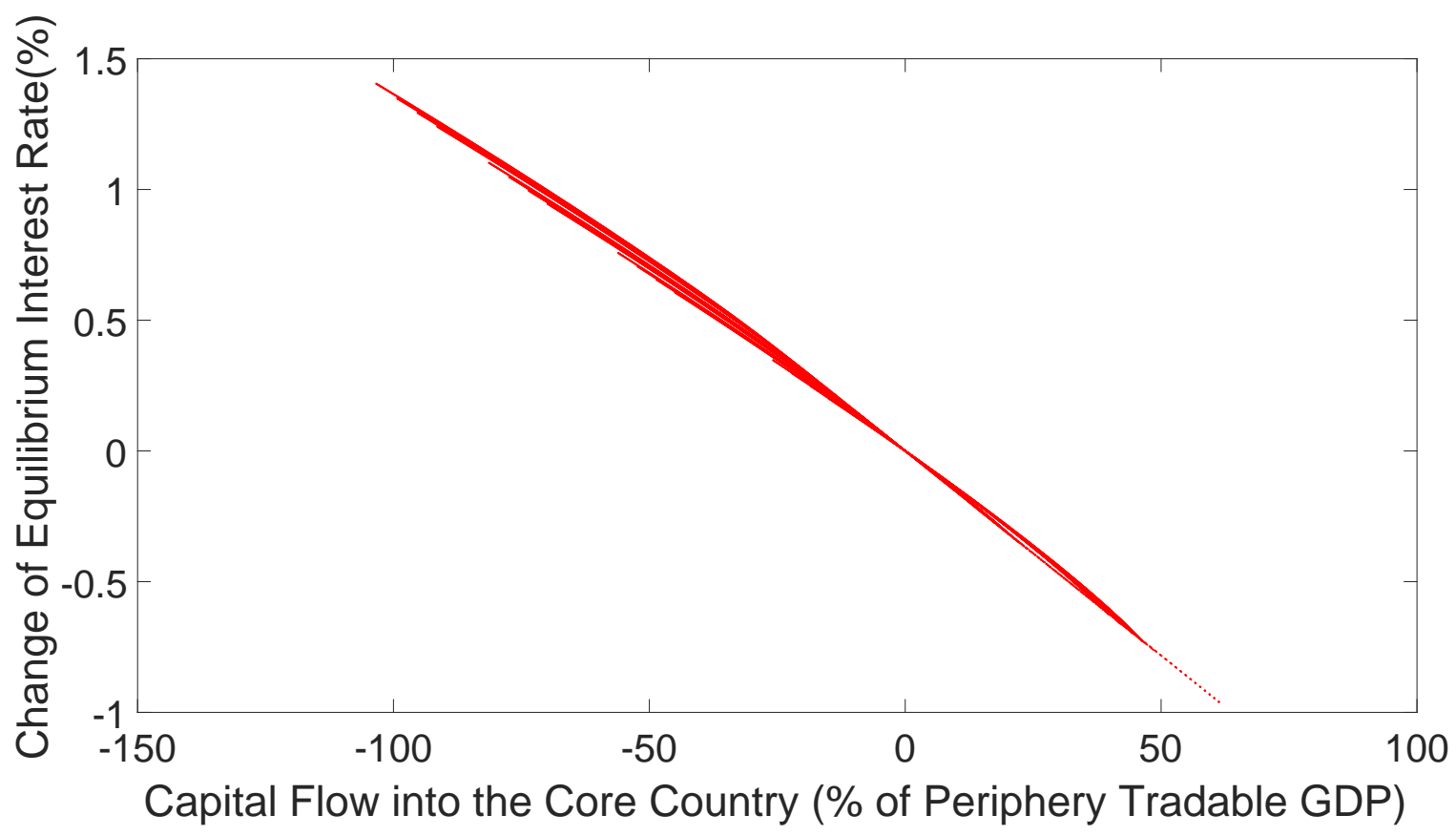

Figure 1: Response of the World Interest Rate to Capital Flows

peripheral countries increase their foreign asset position by 100 billion dollars. ${ }^{1}$ This number falls in the range of empirical estimates of the foreign capital flow's impact on U.S. interest rates. For example, the U.S. interest rate would go down by 26 basis points as in Warnock and Warnock (2009) or 70 basis points as in Bernanke et al. (2004) in response to a 100 billion dollar inflow. ${ }^{2}$

5.3 Decision Rules In this section we discuss the decision rules for all three equilibria. We plot the decision rules for the next period bond position in figure 2. As shown in the figure, there is a kink in each of the decision rules and the turning point indicates the point at which the borrowing constraint is satisfied with equality, but is not yet binding. To the right of this point, the borrowing constraint is slack and the policy function displays the common upward-sloping shape. To the left of the kink, the borrowing constraint is binding and the policy function is downward sloping. This is because a reduction of the current bond position when the borrowing constraint is binding leads to a decrease in tradable consumption, which lowers the relative price of nontradable goods and further tightens the borrowing constraint. As a result, when an unfavorable endowment or financial shock realizes, it triggers a binding

\footnotetext{
${ }^{1}$ The average tradable GDP of our country group over the sample period is 320 billion dollars, so 100 billion dollars is equivalent to $31.25 \%$ of average tradable GDP.

${ }^{2}$ Bernanke et al. (2004) finds a 0.7 basis points impact on U.S. long rates from each 1 billion dollar of Japanese foreign exchange intervention. Warnock and Warnock (2009) reports a 19 basis points reduction in U.S. long rates associated with 12-month flows of 1 percent of GDP. 1 percent U.S. average GDP over our sample period is around 72 billion dollars, so the estimates from Warnock and Warnock (2009) then imply 100 billion dollar inflow depresses long rates by 26 basis points.
} 


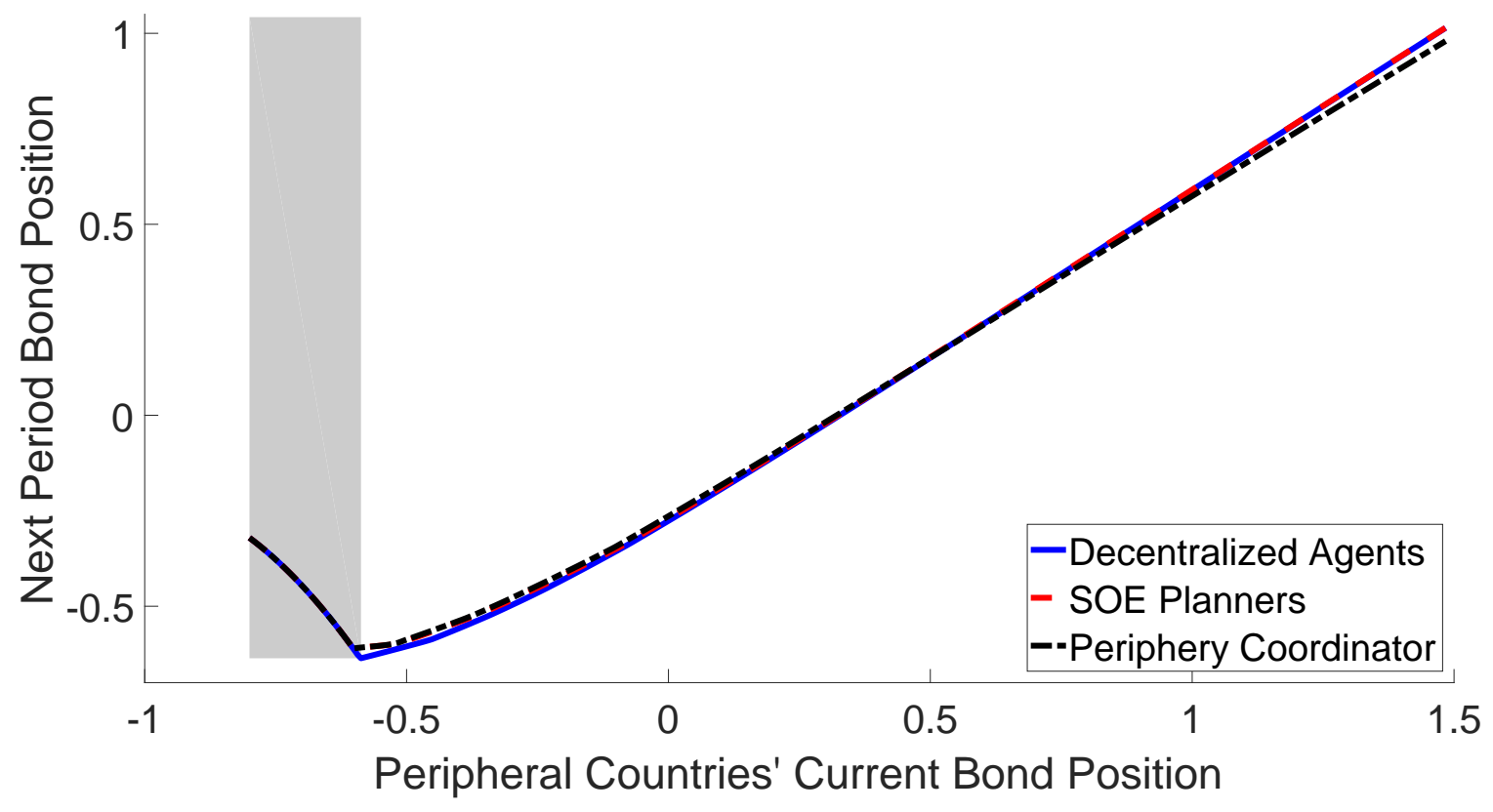

Figure 2: Bond Decision Rules in Three Equilibra

Note: The shaded area indicates that the collateral constraint binds in the decentralized equilibrium.

borrowing constraint, and capital flows out of the peripheral countries.

Figure 3 depicts the difference between the decision rules of the three equilibria. When the borrowing constraint is binding, the decision rules are identical in all three equilibria. However, as the bond position approaches the binding region from the right, the SOE planners and the periphery coordinator borrow less than the decentralized agents because of the internalization of the pecuniary externality. In addition to the precautionary saving motive, the periphery coordinator also takes into account the general equilibrium effect of aggregate bond decisions on the world interest rate. As a result, the periphery coordinator borrows less than the SOE planners when the bond position approaches the binding region.

As the bond position moves away from the binding region and the peripheral countries accumulate more assets, the probability of having a binding collateral constraint in the next period diminishes. As a consequence, the benefit of internalizing the pecuniary externality vanishes. This leads to the SOE planners' decision rule approaching that of the decentralized agents' in the far right. In contrast, as the bond position increases, the periphery coordinator chooses a lower bond position compared to the decentralized agents and the SOE planners in order to obtain favorable interest rate movements. As highlighted in lemma 2, the difference between the bond choices widens when the bond position is further away from zero. This result is novel to the macro-prudential policy literature as the existing literature assumes the world interest rate is fixed and is not affected by the decisions of any single SOE.

Table 3 reports the average NFA position and the probability of crisis in the three equi- 


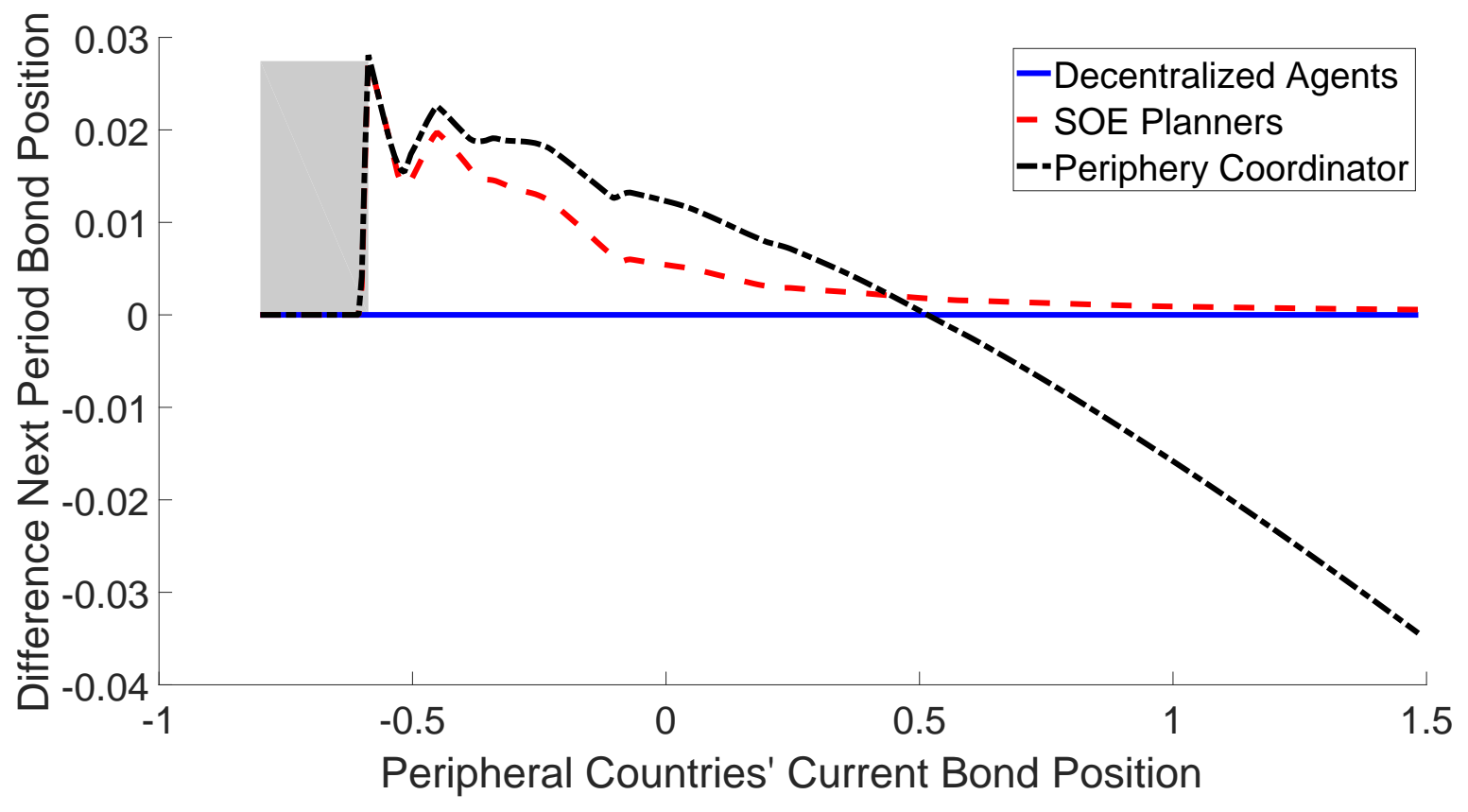

Figure 3: The Difference between Bond Decision Rules

Note: The red dashed line (black dotted line) plots the difference between the decision rules of the SOE planner (periphery coordinator) and the decentralized agents. A positive number means that the SOE planner (periphery coordinator) chooses a higher bond position than the decentralized agents. The shaded area indicates that the collateral constraint binds in the decentralized equilibrium.

libria. To calculate the NFA position, the probability of crisis, and other time series statistics, we simulate the economy for 100,000 periods, discard the first 10,000 periods, and repeat the simulation 30 times. We take the average of the time series statistics from the 30 simulations. The NFA position is calculated as the ratio of bond position over tradable GDP. Similar to Benigno et al. (2013), we define a crisis in the model as an event which: (1) The borrowing constraint is binding and (2) there is an outflow of capital $\left(b_{t+1}>b_{t}\right)$.

Our simulation results show that the peripheral countries are net savers on average as in the data. Proposition 2 states that when the peripheral countries are saving in the international financial market, the periphery coordinator prefers a lower bond choice than the SOE planners; however, they may choose a higher or lower position relative to the decentralized agents. Our numerical analysis confirms this finding: the periphery coordinator's average NFA position is $53 \%$ of the SOE planners' level. In addition, in our baseline calibration, the periphery coordinator's motivation to exert market power dominates the incentive to internalize the pecuniary externality. The result is that the periphery coordinator's average NFA position is about $56 \%$ of the decentralized agents' level.

Table 3 also reports the probability of a crisis based on the crisis definition above. Both the SOE planners and the periphery coordinator reduce the probability of crisis relative to the decentralized equilibrium. Note that the probability of crisis under the decentralized 


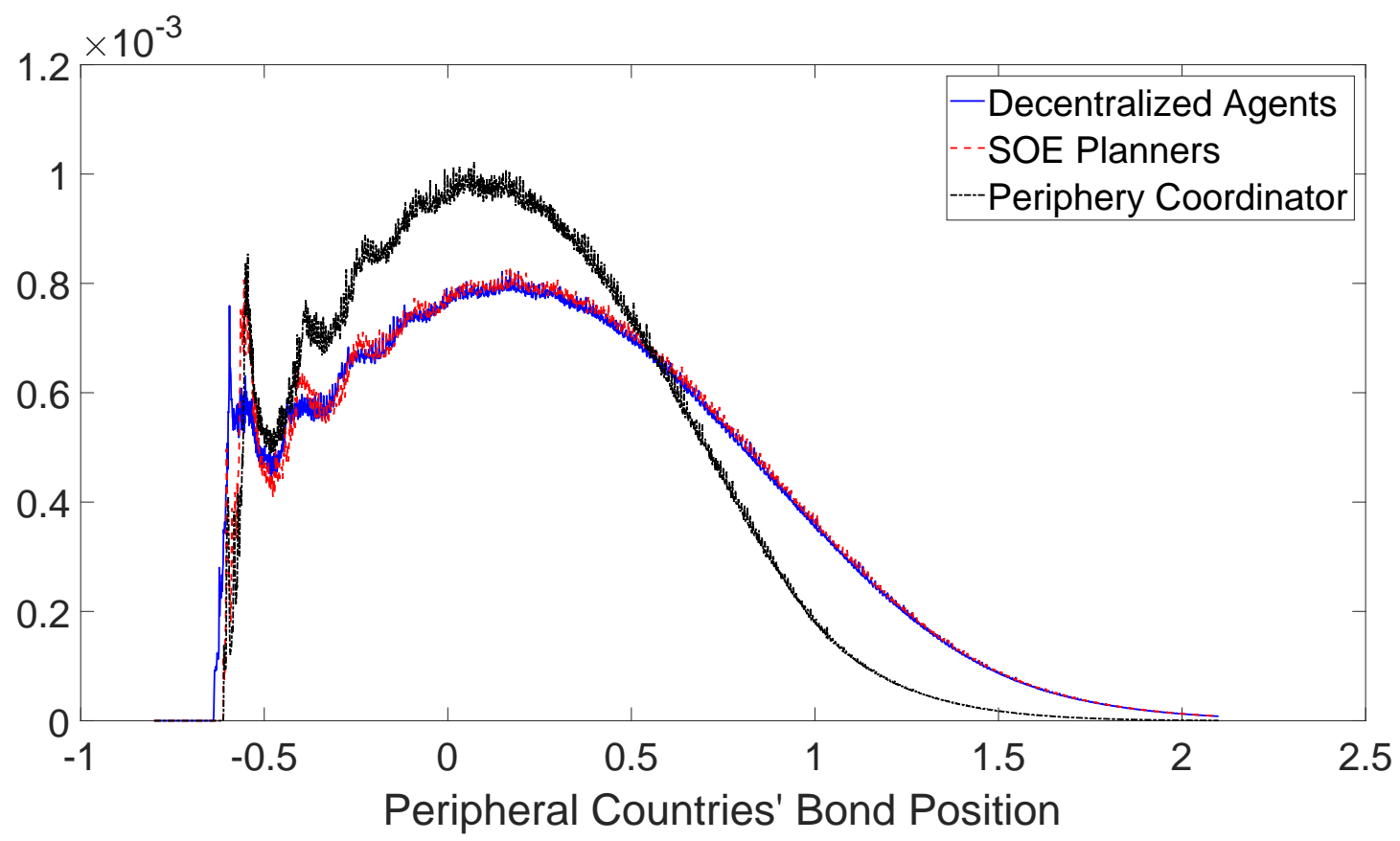

Figure 4: Ergodic Distributions of Bond Positions in the Three Equilibria

equilibrium (0.39\%) is noticeably lower than the probability of crisis in Bianchi (2011) (5.5\%). This is because in Bianchi (2011), the decentralized agents in the SOE are impatient relative to the rest of the world ${ }^{1}$ and thus always try to front load consumption until they hit the borrowing constraint. However, in our baseline calibration, the agents in peripheral countries are not impatient relative to the core country and they accumulate net external wealth to self insure themselves as in the data. ${ }^{2}$ As a result, our baseline calibration generates a much lower probability of crisis in the peripheral countries than in Bianchi (2011). In section 5.6, we show that our model can generate a crisis probability of comparable magnitude to that in Bianchi (2011) when the peripheral countries are impatient relative to the core country.

Figure 4 plots the ergodic distributions of the peripheral countries' bond position for all three equilibria. All three ergodic bond distributions displayed are truncated on the left as a result of the peripheral countries' inability to borrow beyond this point due to the collateral constraint. Recall that figure 3 shows the SOE planners always choose a higher bond position than the decentralized agents. Therefore, the bond distribution of the SOE planners is slightly to the right of the decentralized equilibrium. On the other hand, the periphery coordinator prefers a lower bond position than decentralized agents when the peripheral countries are saving and prefers a higher bond position when they are borrowing. Consequently, the periphery coordinator has a lower probability of having extreme bond positions and the bond distribution is more concentrated than the one in the decentralized equilibrium.

\footnotetext{
${ }^{1}$ Bianchi (2011) sets $\beta(1+r)=0.946$.

${ }^{2}$ We explain why we choose net creditor countries as our sample in the calibration section.
} 
Table 3: Summary Statistics in the Three Equilibria

\begin{tabular}{lccc}
\hline \hline Average NFAs of Periphery & Decentralized & SOE Planner & Periphery Coordinator \\
\hline (Percentage of tradable GDP) & $27.97 \%$ & $29.17 \%$ & $15.60 \%$ \\
\hline \hline Crisis Probability in Periphery & Decentralized & SOE Planner & Periphery Coordinator \\
\hline (Percent per year) & $0.39 \%$ & $0.26 \%$ & $0.23 \%$ \\
\hline \hline Welfare Gain in Periphery & Decentralized & SOE Planner & Periphery Coordinator \\
\hline $\begin{array}{lccc}\text { (Percentage of permanent composite consumption) } \\
\text { Welfare Gain in Core }\end{array}$ & $\begin{array}{l}\text { Decentralized } \\
\text { (Percentage of constant consumption over life) } \\
\text { - SOE Planner }\end{array}$ & Periphery Coordinator \\
\hline
\end{tabular}

\subsection{WELFARE COMPARISONS}

5.4.1 Welfare of the Peripheral Countries We now compare the welfare outcomes of the periphery countries across the three equilibria. The welfare gains are measured as a percentage of permanent consumption that the decentralized agents are willing to give up to live in the world with either the SOE planners or the periphery coordinator. Table 3 shows that the coordinated allocation dominates the other two equilibria in terms of the welfare of the peripheral countries, while the uncoordinated allocation results in a negligible welfare gain relative to the decentralized allocations. To compute the state-contingent welfare gain, we first obtain the decentralized agents' value function by iterating the decision rules $\left\{c, b^{\prime}\right\}$ :

$$
V^{D E}(b, y, \kappa)=\frac{c(b, y, \kappa)^{1-\gamma}}{1-\gamma}+\beta E V^{D E}\left(b^{\prime}(b, y, \kappa), y^{\prime}, \kappa^{\prime}\right)
$$

Since the constant relative risk aversion utility function is homothetic, the state-contingent welfare gain $\tau^{h}(b, y, \kappa)$ can be calculated by,

$$
\left(1+\tau^{h}(b, y, \kappa)\right)^{1-\gamma} V^{D E}(b, y, \kappa)=V^{h}(b, y, \kappa)
$$

where $h \in\{S O E P, P C\}$.

Figure 5 plots the state contingent welfare gain under the uncoordinated and coordinated regulations. The uncoordinated national regulations deliver a positive welfare gain for the peripheral countries in most states, but not all. Near the binding region, the welfare gain resulting from the uncoordinated regulations is the largest. This is a result of macro-prudential policy intervention being most effective when the economy is approaching a financial crises. On the other hand, as the current bond position increases, the welfare gain from uncoordinated regulations falls and eventually becomes negative. This is because of the cost of unfavorable world interest rate movements outweighing the benefit of increased financial stability. Since the benefit of financial stabilization from the uncoordinated macro-prudential policies is partially offset by the loss from a suppressed rate of return on savings, the average welfare 


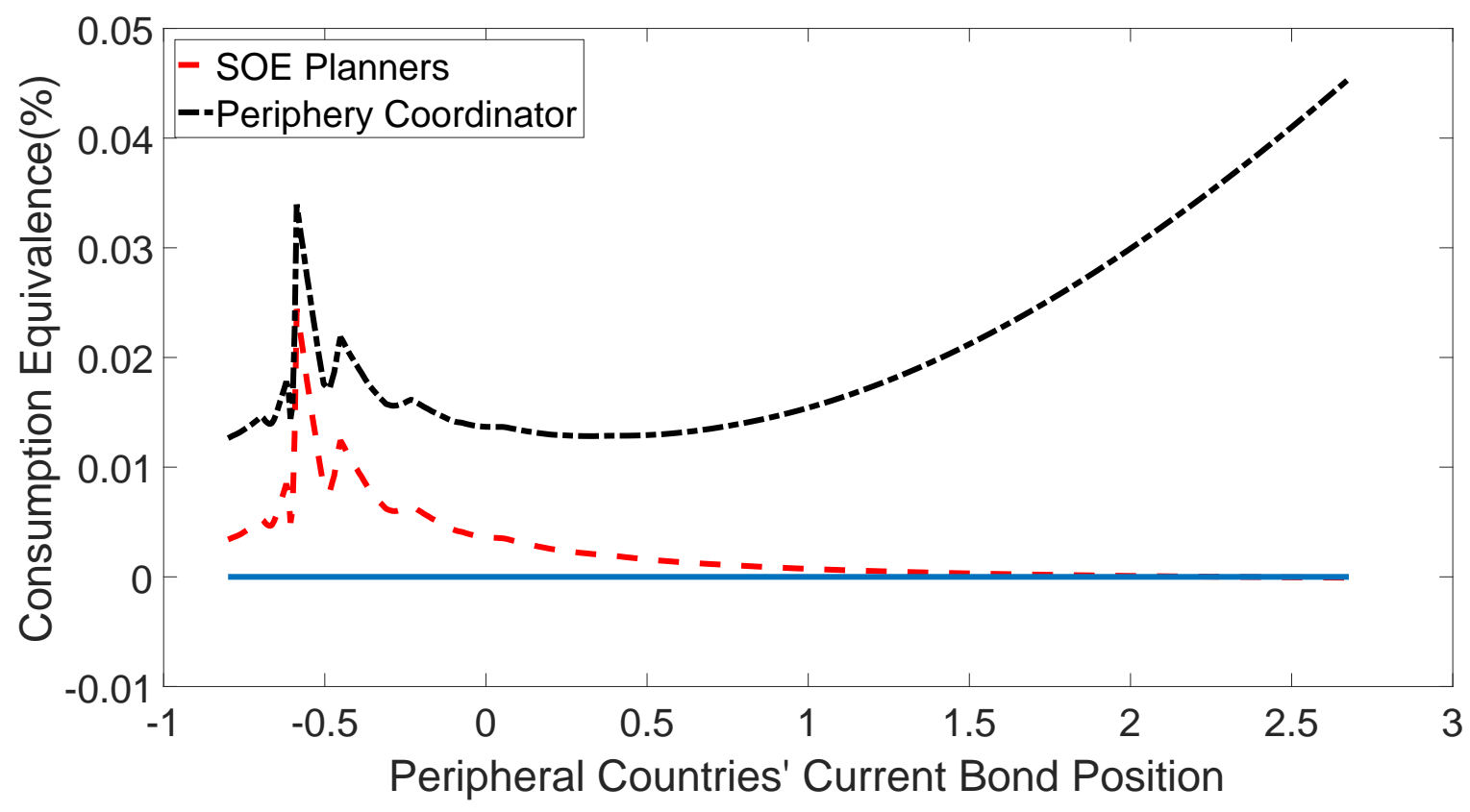

Figure 5: State-Contingent Welfare Gains of the Peripheral Countries

Note: This figure shows the state-contingent welfare gains of the peripheral countries that the SOE planners and periphery coordinator achieve. The welfare gains are measured as percentage of permanent consumption that the decentralized agents are willing to give up to live in the world with either the SOE planners or the periphery coordinator.

gain $^{1}$ is negligible at $0.001 \%$ of permanent lifetime consumption.

The periphery coordinator's welfare gain also peaks near the binding region for the same reason discussed above. However, when the peripheral countries have a positive bond position, the welfare gain rises with the bond position as the benefit of strategic interest rate manipulations increase. On average, the welfare gain from periphery coordination is $0.021 \%$ of permanent lifetime consumption. Moreover, the welfare gains from coordination always dominate those obtained from non-coordination. This finding highlights the importance of super-national policy coordination among EMEs, and the potential dangers of national regulations failing to acknowledge their impact on the world interest rate.

\subsubsection{Welfare OF THE CORE COUNTRY We also explore the welfare implications of pe-} riphery coordination on the core country in the three equilibria. Since the core country is populated by overlapping generation agents, we use a different approach to calculate the welfare gains. We follow Devereux and Yu (2014) to calculate the certainty equivalence of effective consumption to measure the welfare of the core country. The conditional lifetime utility of a representative agent in the core country who is born in period $t$ is defined as:

\footnotetext{
${ }^{1}$ The average welfare gains are calculated by integrating the welfare gain functions in figure 5 with respect to the bond position distribution in competitive equilibrium. Using the bond position distributions in the other two equilibria yields the same rank of welfare and does not change our result qualitatively.
} 


$$
W e l^{* h}=\mathbb{E}\left\{\log \left(c_{t}^{* h}\right)+\beta^{*} \log \left(c_{t+1}^{* h}\right)\right\}
$$

where $h \in\{C E, S O E P, P C\}$ represents the three equilibria in this paper. The expectation is taken with respect to the bond position distributions and the core country's consumption is calculated using the market clearing conditions and the peripheral country agents' decision rules. We find a certainty equivalence of effective consumption $\tilde{c}^{h}$ given by:

$$
W e l^{* h}=\log \left(\tilde{c}^{* h}\right)+\beta^{*} \log \left(\tilde{c}^{* h}\right)=\left(1+\beta^{*}\right) \log \left(\tilde{c}^{* h}\right)
$$

Rearranging the terms yields:

$$
\tilde{c}^{* h}=\exp \left(\frac{W e l^{* h}}{1+\beta^{*}}\right)
$$

We measure the welfare gain $\tau^{* h}$ as the percentage of certainty equivalence of effective consumption over the competitive equilibrium level:

$$
\tau^{* h}=\frac{\tilde{c}^{* h}}{\tilde{c}^{* C E}}-1
$$

where $h \in\{S O E P, P C\}$.

As shown in table 3, the SOE planners do not take into consideration their savings decision's impact on the world interest rate, yielding a small positive welfare gain $\left(6.62 \times 10^{-6 \%}\right)$ for the core country. On the other hand, the periphery coordinator exerts market power and causes a welfare loss for the core country. In our baseline calibration, the welfare gain and loss for the core country are small since we set the size of the core country to be much larger than the peripheral countries in order to match the elasticity of the world interest rate.

5.5 Decentralization In section 4.4, we analytically show that the allocations of the SOE planners and the periphery coordinator can be restored by imposing a tax on the decentralized agents' bond decisions. In this section, we calculate the state-contingent tax rates numerically and plot them in figure 6 .

The SOE planners levy a positive tax rate on the decentralized agents' bond holdings when the current bond position is close to the binding area, and decays to zero as the bond position moves away from the constrained region. As in Bianchi (2011), this capital flow tax acts as a macro-prudential policy instrument that discourages excessive borrowing. On the other hand, the periphery coordinator imposes a positive and higher tax rate on the bond decisions relative to the SOE planners when the peripheral countries are borrowing, but a negative tax rate when they are saving. The higher positive tax rate increases the decentralized agents' cost to borrow and thus reduces borrowing in the peripheral countries in an effort to maintain a lower interest rate. Similarly, the negative tax rate discourages saving at an unnecessarily low interest rate. 


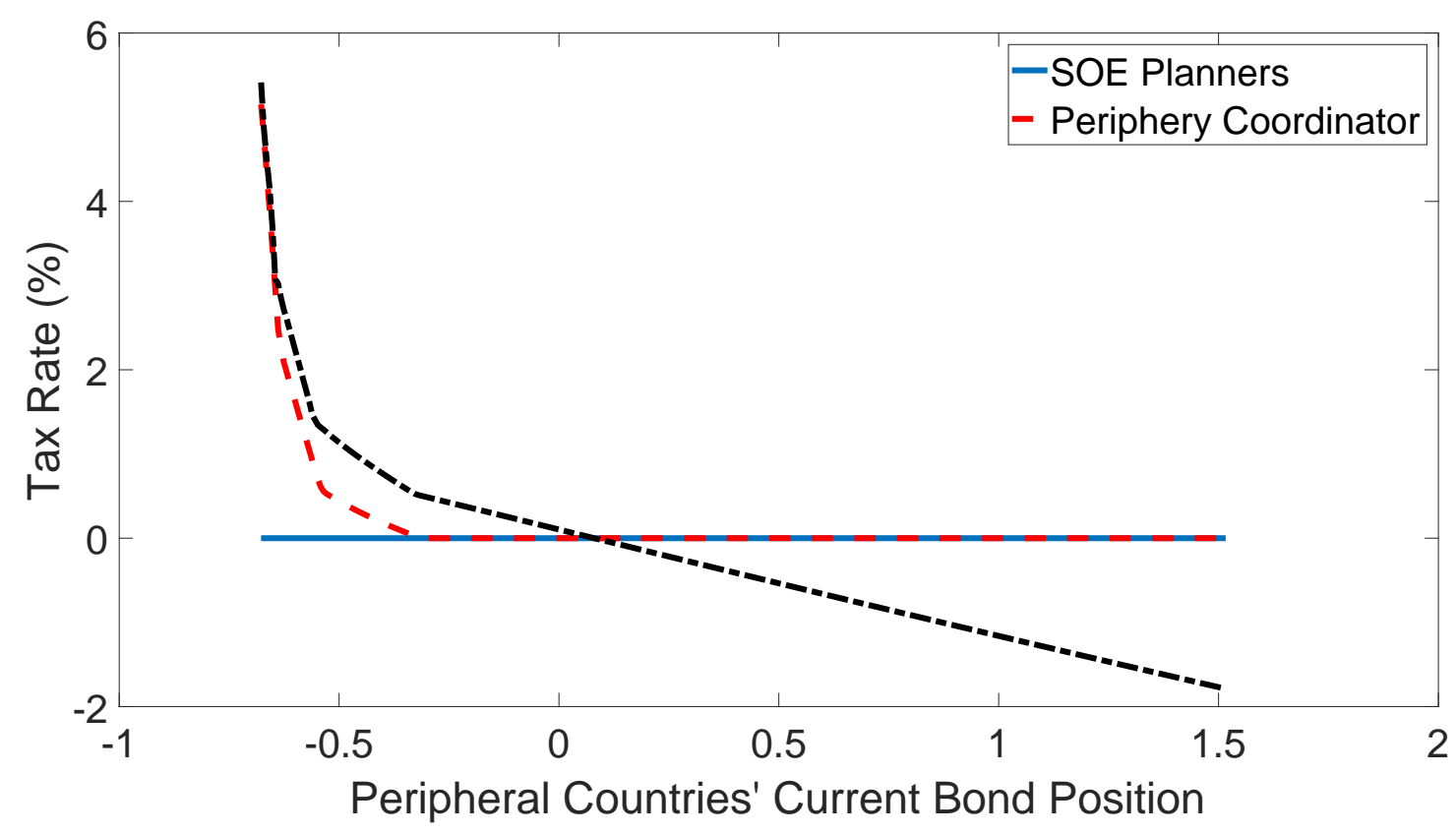

Figure 6: State-Contingent Taxes to Implement SOE Planners' and Coordinator's Allocations Note: The tax is imposed on the decentralized agents' next period bond decision.

5.6 COMPARATIVE STATICS In this section we perform sensitivity analysis with respect to our numerical results.

Discount Factor Figure 7 shows the average NFA position, the probability of crisis, and the welfare gain when we vary the peripheral countries' discount factor $\beta$. When the peripheral countries are impatient compared to the core country (low $\beta$ ), the decentralized agents (blue solid line) always try to borrow and therefore have a negative average NFA position. As a result, the peripheral countries experience a higher probability of crisis, and the national macro-prudential policy achieves a positive welfare gain by reducing the probability of financial crisis. As the peripheral countries become more patient ( $\beta$ rises), the average bond position increases, and the welfare gain from internalizing the pecuniary externality vanishes since financial crisis occur with a lower probability. When $\beta$ exceeds 0.955 , the welfare loss caused by excessive savings dominates the welfare gain from increased financial stability. The end result is national macro-prudential policy generating a welfare loss for the peripheral countries.

When the peripheral countries are impatient (low $\beta$ ), the periphery coordinator has the highest average NFA position (smallest debt) among the three equilibria in order to prevent financial crises as well as maintaining a low interest rate. When the peripheral countries are patient (high $\beta$ ), they become net creditors, and then the periphery coordinator has the lowest average NFA position. As $\beta$ increases, the peripheral countries accumulate more assets and the periphery coordinator exerts more monopoly power when making savings decisions. 

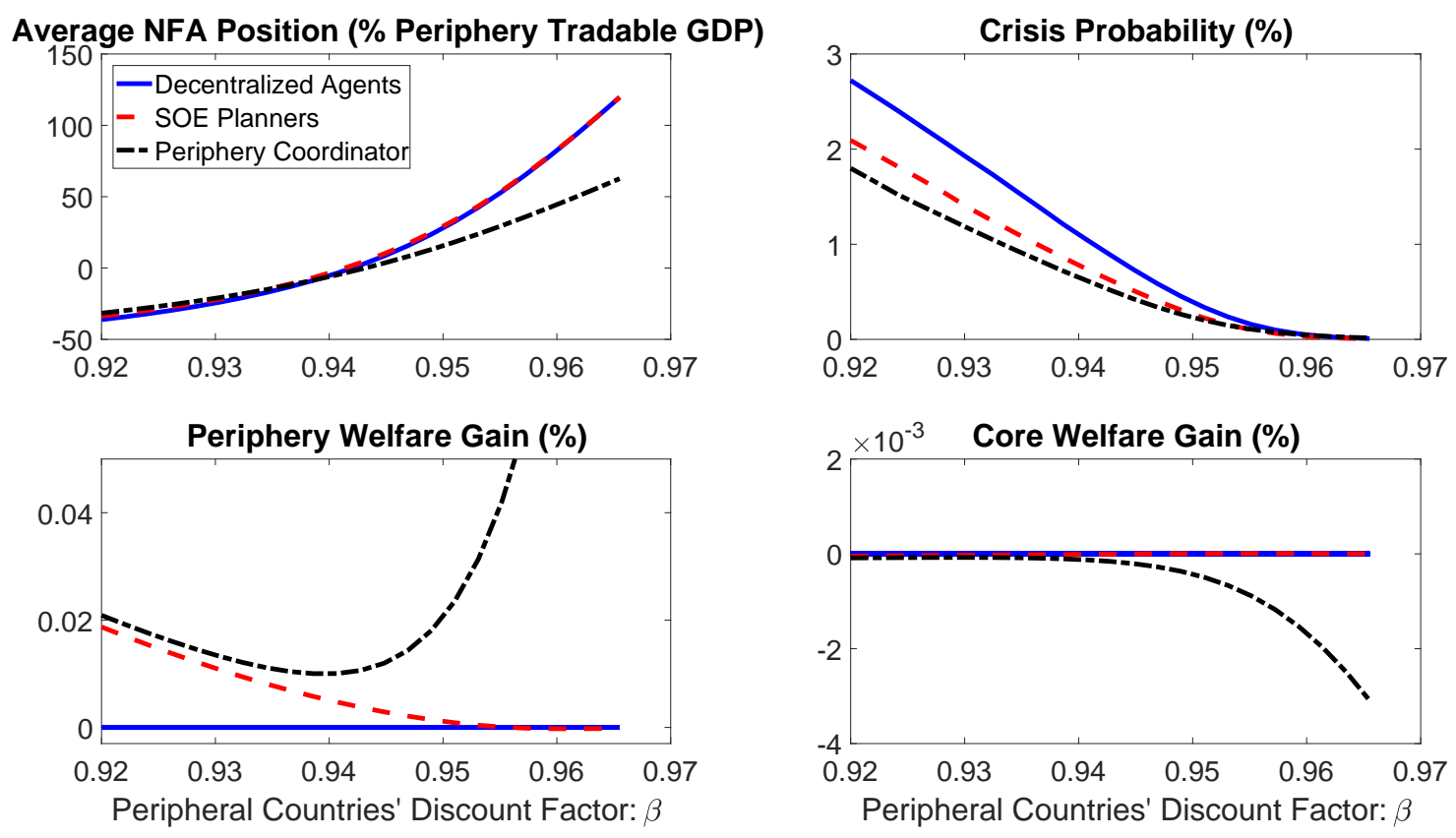

Figure 7: Comparative Statics - Peripheral Countries' Discount Factor $\beta$

Therefore, the difference in average NFA positions between the periphery coordinator and the other two equilibria widens as the welfare loss of the core country increases with $\beta$.

Risk Aversion Figure 8 reports the model statistics when we vary the risk aversion parameter $\gamma$ of the peripheral countries. The peripheral countries accumulate more assets when the risk aversion parameter $\gamma$ increases. The ranking of average NFA positions and welfare results are robust to changes in $\gamma$. As the average NFA position increases with $\gamma$, the periphery coordinator achieves higher welfare gains for the peripheral countries at the cost of larger welfare losses for the core country. For the probability of financial crisis, both the SOE planners and the periphery coordinator have lower probabilities of crisis relative to the decentralized equilibrium. However, the periphery coordinator does not always lower the probability of crisis relative to the SOE planners. This is because as the peripheral countries become more risk averse and hold higher average NFA positions, the periphery coordinator chooses much lower NFA positions to obtain a higher rate of return. As a result, the periphery coordinator's allocations may generate a higher probability of financial crisis but yield larger welfare gains relative to the SOE planners' allocations.

World Interest Rate Elasticity In section 5.2 we calibrate the size of the core country to match the interest rate elasticity found in the literature and we show that the baseline calibration can generate a reasonable elasticity of the world interest rate. Now we vary the size of the core country in order to cover the entire range of the elasticity of the world interest rate found 

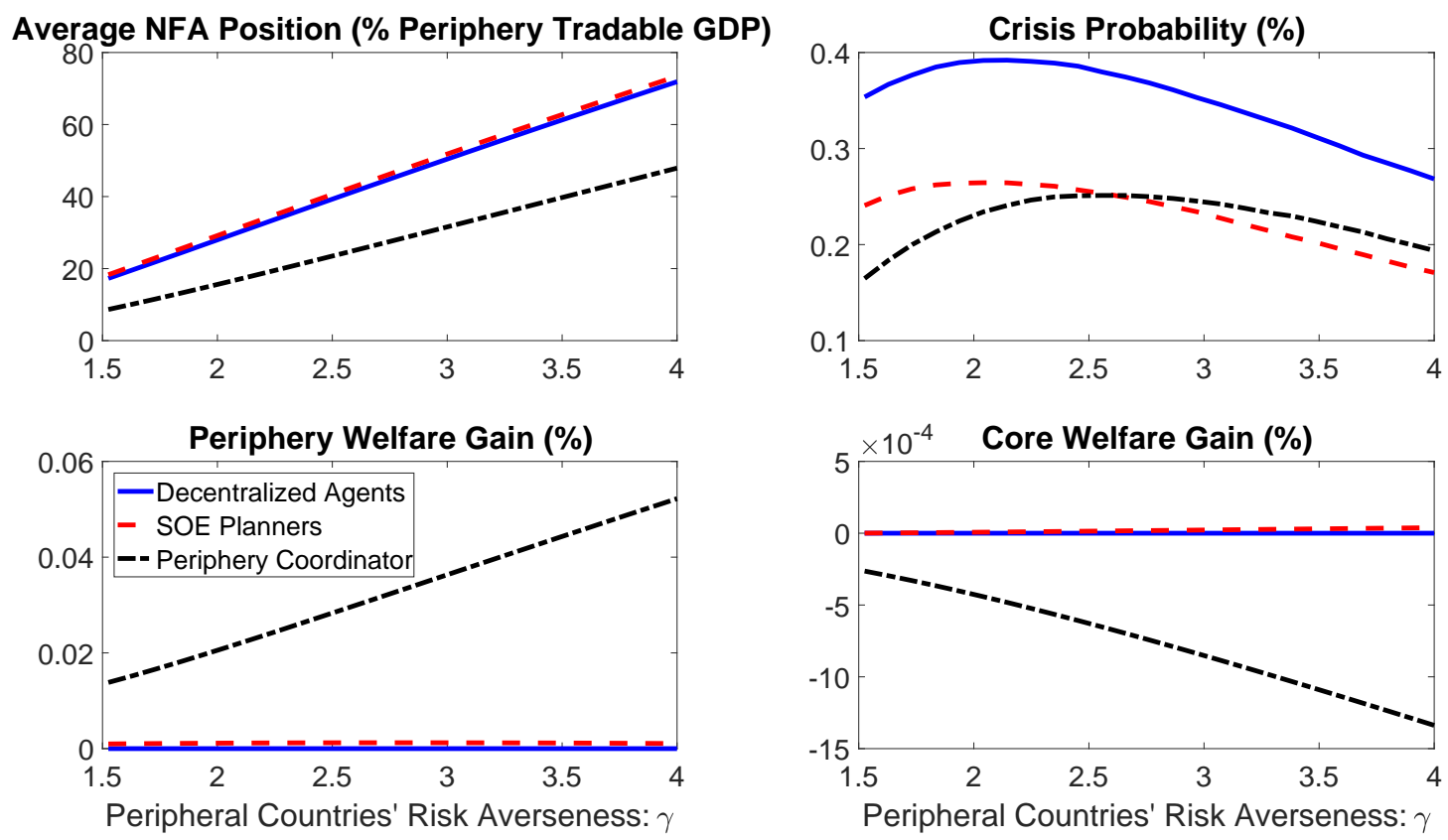

Figure 8: Comparative Statics - Peipheral countries' Risk Averseness $\gamma$

in the empirical studies ${ }^{1}$ and investigate how the model moments change with the elasticity of the world interest rate. After varying the size of the core country, we solve the model and re-run the regression in section 5.2:

change of equilibrium interest rate $=\beta_{0}$

$$
+\beta_{1} * \text { capital flow into the core country }+ \text { error term }
$$

In this regression, $\beta_{1}$ is always negative and thus its absolute value measures the elasticity of the world interest rate to the capital flows into the core country. A lower value of $\beta_{1}$ (higher absolute value) indicates a higher world interest rate elasticity. We find that the qualitative and quantitative implications are robust to different interest rate elasticities as reported in figure 9. The periphery coordinator always yields the lowest and the SOE planners always yield the highest average NFA position among the three equilibria. A higher world interest rate elasticity discourages the peripheral countries from adjusting their bond position since the world interest rate responds more aggressively to the capital flows. As a result, the average NFA position in the peripheral countries decreases when the interest rate becomes more elastic.

\footnotetext{
${ }^{1}$ As mentioned in section 5.2, the estimates from Warnock and Warnock (2009) and Bernanke et al. (2004) suggest that the U.S interest rate would go down by 26 and 70 basis points respectively for every 100 billion dollars in capital inflows. Our comparative static analysis covers the elasticity range from 9.4 basis points to 70.6 basis points.
} 

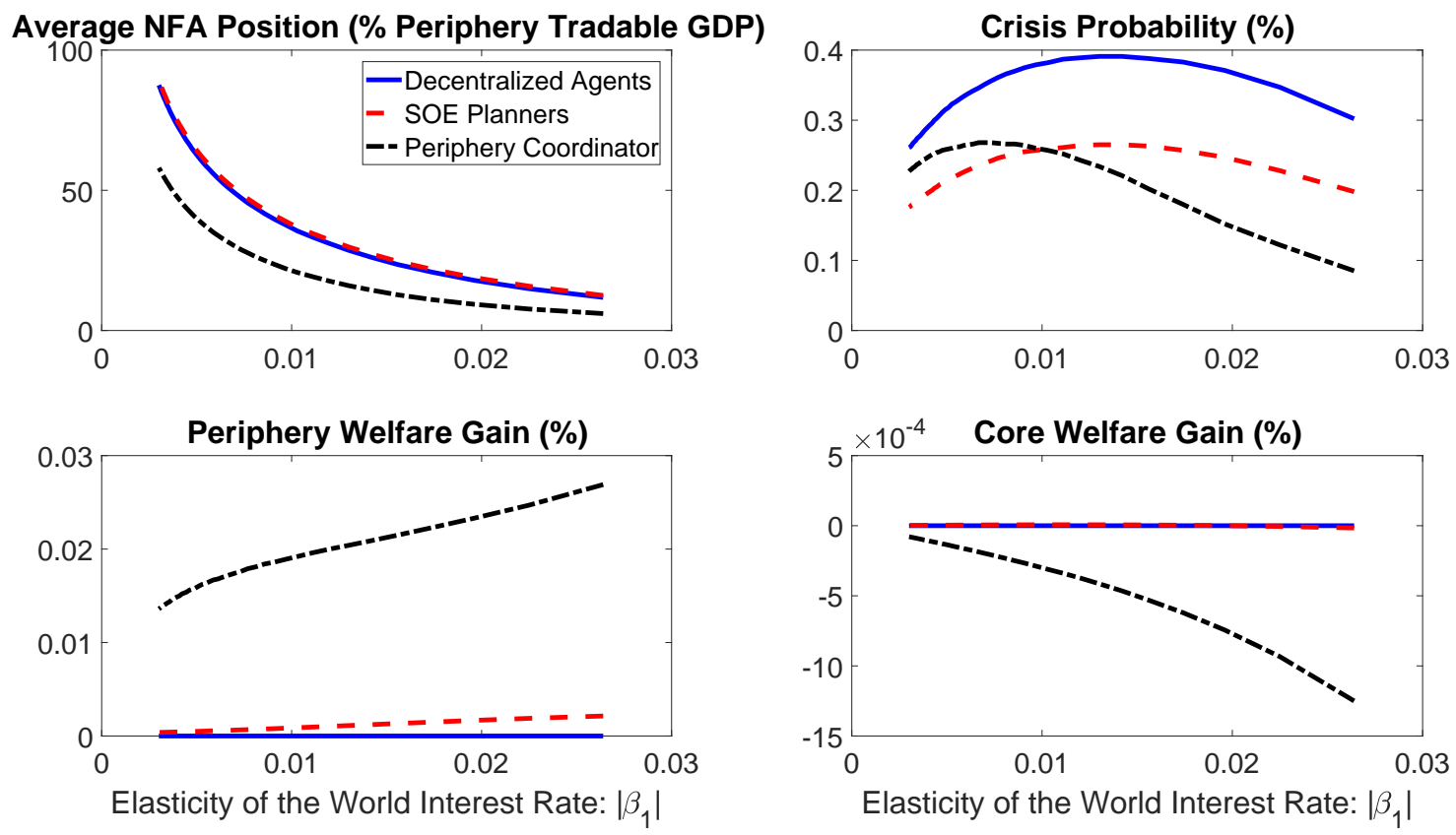

Figure 9: Comparative Statics - the Elasticity of the World Interest Rate $\left|\beta_{1}\right|$

Note: In this figure, we adjust the elasticity of the world interest rate by varying the size of the core country and show how the model moments change with the elasticity. The $x$-axis is the absolute value of the coefficient $\beta_{1}$ from the regression (5.8). In this regression, $\beta_{1}$ is always negative and its absolute value measures the elasticity of the world interest rate to the capital flows into the core country. A lower value of $\beta_{1}$ (higher absolute value) indicates a higher world interest rate elasticity and vice versa.

We also find that the periphery coordinator always chooses a significantly lower average NFA position (below $70 \%$ ) relative to the SOE planners over this range of elasticities. The SOE planners and the periphery coordinator have lower probabilities of crisis than the decentralized equilibrium. When the elasticity of the world interest rate is high, the periphery coordinator generates a lower crisis probability than the SOE planners since he discourages borrowing more aggressively in order to reduce the cost of borrowing. However, when the elasticity is low and the average NFA position of the peripheral countries are high, the periphery coordinator chooses to have a lower average NFA position to maintain a higher return on savings at the cost of having a higher probability of crisis.

The lower panels of figure 9 show the welfare gains of peripheral countries and the core country. When the elasticity of the world interest rate increases, the periphery coordinator has more market power in the international financial market so that the welfare gain from coordination rises. We find that the welfare gain from coordination is always substantial (from $0.014 \%$ to $0.027 \%$ consumption equivalence) over this range of elasticities, while the uncoordinated policy yields much smaller gains (from $3.85 \times 10^{-4} \%$ to $0.002 \%$ consumption equivalence). 


\section{CONCLUSIONS}

We develop a two sector, core-periphery country general equilibrium model with endogenous financial crises to study the optimal foreign asset accumulation for EMEs. The key insight from our analysis lies in the interaction between two considerations: financial stability and strategic world interest rate manipulation. Individual EME regulators only internalize the pecuniary externality at the national level, hence always encourage savings (discourage borrowing) to prevent financial crises. In contrast, a coordinator for all EMEs prefers a different asset position relative to the national planners. This is because the coordinator realizes the impact of aggregate savings on the world interest rate in general equilibrium, a fact missed by national regulators.

We calibrate our model to a group of Asian EMEs. Our quantitative result shows that the coordinated NFA level is 53\% of the uncoordinated level. More importantly, our analysis demonstrates that uncoordinated country-level foreign asset accumulations may not always enhance welfare once the variable world interest rate is taken into consideration. Our results thus suggest macro-prudential policy analysis for EMEs based on partial equilibrium models may be misguided, and costly in terms of welfare.

Our analysis calls for policy coordination among EMEs on foreign asset accumulations. We acknowledge that the implementation of such coordination is challenging, but there may be substantial welfare gains associated with it. The establishment of a reserve pool for groups of EMEs may be a feasible first step. As outlined in Farhi et al. (2011), reserve pooling provides better access to liquidity and higher financial returns relative to self-insurance. ${ }^{1}$ A limitation of our current analysis is that we assume all EMEs are identical and subject to the same shocks. We leave the design of policy coordination when EMEs are heterogeneous and subject to idiosyncratic shocks to future research. In addition, we restrict the agents in the core country as overlapping generations so that it is sufficient to consider current capital flows alone, but this assumption leaves out the intertemporal terms-of-trade effect presented in Costinot et al. (2014). It would be useful to relax this assumption in future work. Finally, the core country is excluded from our welfare analysis of periphery policy coordination. It is interesting to study global policy coordination in this framework.

\footnotetext{
${ }^{1}$ We view the Chiang Mai Initiative, which is a multilateral currency swap arrangement among the ASEAN+3 countries that draws from a foreign exchange reserves pool, as a first step in the coordination of these countries' foreign assets accumulation practices. Although the explicit objective of the initiative is to "provide sufficient and timely financial support to ensure financial stability in the East Asian region". Implicitly the manager of the reserves pool can exploit monopoly power in the international financial market to obtain higher financial returns.
} 


\section{REFERENCES}

Bardhan, P. K. (1967). Optimum foreign borrowing. Essays on the Theory of Optimal Economic Growth, 117-128.

Baxter, M. (1991). Approximating suboptimal dynamic equilibria: An euler equation approach. Journal of Monetary Economics 28(2), 173-200.

Bengui, J. (2013). Macro-prudential policy coordination. manuscript, University of Montreal.

Benigno, G., H. Chen, C. Otrok, A. Rebucci, and E. R. Young (2013). Financial crises and macro-prudential policies. Journal of International Economics 89(2), 453-470.

Bernanke, B. (2005). The global saving glut and the us current account deficit. Technical report, Board of Governors of the Federal Reserve System (US).

Bernanke, B., V. Reinhart, and B. Sack (2004). Monetary policy alternatives at the zero bound: An empirical assessment. Brookings papers on economic activity 2004(2), 1-100.

Bianchi, J. (2011). Overborrowing and systemic externalities in the business cycle. The American Economic Review 101(7), 3400.

Bianchi, J. and E. G. Mendoza (2013). Optimal time-consistent macroprudential policy. Working paper, National Bureau of Economic Research.

Caballero, R. J. and A. Krishnamurthy (2001). International and domestic collateral constraints in a model of emerging market crises. Journal of monetary Economics 48(3), 513-548.

Caballero, R. J. and A. Krishnamurthy (2003). Excessive dollar debt: Financial development and underinsurance. The Journal of Finance 58(2), 867-894.

Coleman, W. J. (1991). Equilibrium in a production economy with an income tax. Econometrica: Journal of the Econometric Society, 1091-1104.

Cooper, R. N. (1985). Economic interdependence and coordination of economic policies. Handbook of international economics 2, 1195-1234.

Costinot, A., G. Lorenzoni, and I. Werning (2014). A theory of capital controls as dynamic terms-of-trade manipulation. Journal of Political Economy 122(1), 77-128.

DáVila, E. and A. Korinek (2017). Pecuniary externalities in economies with financial frictions. The Review of Economic Studies, forthcoming.

Devereux, M. B. and C. Yu (2014). International financial integration and crisis contagion. Technical report, National Bureau of Economic Research. 
Farhi, E., M. Golosov, and A. Tsyvinski (2009). A theory of liquidity and regulation of financial intermediation. The Review of Economic Studies, 973-992.

Farhi, E., P.-O. Gourinchas, and H. Rey (2011). Reforming the international monetary system. CEPR.

Gonzalez-Rozada, M. and P. A. Neumeyer (2003). The elasticity of substitution in demand for non-tradable goods in latin america. case study: Argentina.

Hamada, K. (1966). Strategic aspects of taxation on foreign investment income. The Quarterly Journal of Economics, 361-375.

Hamada, K. (1976). A strategic analysis of monetary interdependence. Journal of Political Economy 84(4, Part 1), 677-700.

Harberger, A. (1985). Lesson for debtor-country managers and policymakers. International Debt and the Developing Countries.

IMF (2010). How did emerging markets cope in the crisis? Technical report, IMF.

Jeanne, O. and A. Korinek (2010). Managing credit booms and busts: A pigouvian taxation approach. Technical report, National Bureau of Economic Research.

Jermann, U. and V. Quadrini (2012). Macroeconomic effects of financial shocks. The American Economic Review 102(1), 238-271.

Kara, G. I. (2016). Systemic risk, international regulation, and the limits of coordination. Journal of International Economics 99, 192-222.

Korinek, A. (2010). Regulating capital flows to emerging markets: An externality view.

Korinek, A. (2011). Capital flows, crises and externalities.

Korinek, A. (2016). Currency wars or efficient spillovers? a general theory of international policy cooperation.

Lorenzoni, G. (2008). Inefficient credit booms. The Review of Economic Studies 75(3), 809-833.

Meller, B. and N. Metiu (2017). The synchronization of credit cycles. Journal of Banking $\mathcal{E}$ Finance.

Mendoza, E. G. (2002). Credit, prices, and crashes: Business cycles with a sudden stop. In preventing currency crises in Emerging Markets, pp. 335-392. University of Chicago Press.

Mendoza, E. G. (2005). Real exchange rate volatility and the price of nontradables in suddenstop-prone economies. Technical report, National Bureau of Economic Research. 
Persson, T. and G. Tabellini (1995). Double-edged incentives: Institutions and policy coordination. Handbook of international economics 3, 1973-2030.

Rabe, C. (2016). Capital controls, competitive depreciation, and the technological frontier. Journal of International Money and Finance 68, 74-102.

Rogoff, K. and M. Obstfeld (1996). Foundations of International Macroeconomics. MIT Press.

Schmitt-Grohé, S. and M. Uribe (2016). Multiple equilibria in open economy models with collateral constraints: Overborrowing revisited. Technical report, National Bureau of Economic Research.

Sergeyev, D. (2014). Financial integration and financial instability. Manuscript, Bocconi University.

Stockman, A. C. and L. L. Tesar (1990). Tastes and technology in a two-country model of the business cycle: Explaining international comovements. Technical report, National Bureau of Economic Research.

Tauchen, G. (1986). Finite state markov-chain approximations to univariate and vector autoregressions. Economics letters 20(2), 177-181.

Warnock, F. E. and V. C. Warnock (2009). International capital flows and us interest rates. Journal of International Money and Finance 28(6), 903-919. 


\section{Appendices}

\section{A PROOFS}

\section{A.1 Proof of Proposition 1}

Proof. When the borrowing constraint is currently not binding, the decentralized Euler equation (4.2) becomes:

$$
U_{T, t}^{d e}=\beta E_{t} R_{t+1} U_{T, t+1}^{d e}
$$

and the representative SOE planner's Euler equation (4.19) becomes:

$$
U_{T, t}^{\text {soep }}=\beta E_{t} R_{t+1} U_{T, t+1}^{\text {soep }}+\beta E_{t} R_{t+1} \mu_{t+1}^{\text {soep }} \Psi_{t+1}^{\text {soep }}
$$

The last term is positive because $\Psi_{t+1}^{\text {soep }}>0$, and $\mu_{t+1}^{\text {soep }}>0$ given the collateral constraint will bind in the next period with a positive probability.

Consider a reallocation of resources by the representative SOE planner starting from the optimal allocations in the decentralized equilibrium. This implies holding one more unit of bonds yields identical marginal costs to the decentralized agents and the SOE planner, $U_{T, t}^{d e}=U_{T, t}^{\text {soep }}$, but higher marginal benefits to the SOE planner because $\beta E_{t} R_{t+1} U_{T, t+1}^{d e}=$ $\beta E_{t} R_{t+1} U_{T, t+1}^{\text {soep }}$ and the last term of (A.2) is positive. Therefore, the SOE planner values bond holdings more than the decentralized agents.

\section{A.2 Proof of Lemma 1}

Proof. Plug in bond market clearing condition (4.5) into (4.3) to yield:

$$
\beta^{*} R_{t+1}\left[y_{1}^{*}+b_{t+1}\right]=y_{2}^{*}-R_{t+1} b_{t+1}
$$

rearrange terms to get an expression for the world interest rate:

$$
R_{t+1}=\frac{y_{2}^{*}}{\left(1+\beta^{*}\right) b_{t+1}+\beta^{*} y_{1}^{*}}
$$

taking first derivative with respect to the periphery countries' bond holdings yields:

$$
\frac{\partial R_{t+1}}{\partial b_{t+1}}=\frac{-\left(1+\beta^{*}\right) y_{2}^{*}}{\left[\left(1+\beta^{*}\right) b_{t+1}+\beta^{*} y_{1}^{*}\right]^{2}}<0
$$

\section{A.3 Proof of LemMa 2}


Proof. Assume the borrowing constraint never binds, then the periphery coordinator's Euler equation (4.23) becomes:

$$
U_{T, t}^{p c}=\beta E_{t} R_{t+1} U_{T, t+1}^{p c}+\beta E_{t} U_{T, t+1}^{p c} b_{t+1} \frac{\partial R_{t+1}}{\partial b_{t+1}} .
$$

Compared to the decentralized Euler equation (A.1), the last term in the equation above is the marginal benefit obtained from interest rate manipulation, normalized by the marginal utility $U_{T, t+1}^{p c}$, and hence measures the coordinator's incentive to strategically manage the world interest rate. Using (A.5), we can show that the first derivative of $b_{t+1}\left(\partial R_{t+1} / \partial b_{t+1}\right)$ is given by:

$$
\frac{\left(1+\beta^{*}\right) y_{2}^{*}\left[\left(1+\beta^{*}\right) b_{t+1}-\beta^{*} y_{1}^{*}\right]}{\left[\left(1+\beta^{*}\right) b_{t+1}+\beta^{*} y_{1}^{*}\right]^{3}} .
$$

We focus on the most empirically relevant parameter space: $\left(1+\beta^{*}\right) b_{t+1}+\beta^{*} y_{1}^{*}>0$ and $\left(1+\beta^{*}\right) b_{t+1}-\beta^{*} y_{1}^{*}<0$. This implies the incentive term $b_{t+1}\left(\partial R_{t+1} / \partial b_{t+1}\right)$ is decreasing in $b_{t+1}$. Given that $\left(\partial R_{t+1} / \partial b_{t+1}\right)<0$ from lemma 1 , it is easy to see when the peripheral countries decide to save $\left(b_{t+1}>0\right), b_{t+1}\left(\partial R_{t+1} / \partial b_{t+1}\right)$ is negative, so the incentive to manipulate the world interest rate is stronger as the saving amount is higher. In contrast, when the peripheral countries decide to borrow $\left(b_{t+1}<0\right), b_{t+1}\left(\partial R_{t+1} / \partial b_{t+1}\right)$ is positive, so the desire to manage the world interest rate is stronger as the borrowing amount is higher.

\section{A.4 Proof of Proposition 2}

Proof. When the borrowing constraint is currently not binding, $\mu_{t}=0$. The periphery coordinator's Euler equation (4.23) becomes:

$$
U_{T, t}^{p c}=\beta E_{t} R_{t+1} U_{T, t+1}^{p c}+\beta E_{t} R_{t+1} \mu_{t+1}^{p c} \Psi_{t+1}^{p c}+\beta E_{t}\left[U_{T, t+1}^{p c}+\mu_{t+1}^{p c} \Psi_{t+1}^{p c}\right] b_{t+1} \frac{\partial R_{t+1}}{\partial b_{t+1}}
$$

Given that the Lagrangian multiplier $\lambda_{t+1}=U_{T, t+1}+\mu_{t+1} \Psi_{t+1}>0$, and $\partial R_{t+1} / \partial b_{t+1}<0$ from Lemma 1, it is obvious when peripheral countries are saving, i.e. $b_{t+1}>0$, the last term of (A.8) is negative. On the other hand, when peripheral countries are borrowing, i.e. $b_{t+1}<0$, the last term of (A.8) is positive.

Next we compare the periphery coordinator's valuation of bond positions relative to the SOE planners and decentralized agents.

Periphery Coordinator vs. SOE planners: Consider a reallocation of resources by the coordinator starting from the SOE planners' optimal allocations. This implies holding one more unit of bonds yields identical marginal costs to the SOE planners and the periphery coordinator, $U_{T, t}^{\text {soep }}=U_{T, t}^{p c}$, but different marginal benefits. Because at the initial allocations, 
$\beta E_{t} R_{t+1} U_{T, t+1}^{\text {soep }}+\beta E_{t} R_{t+1} \mu_{t+1}^{\text {soep }} \Psi_{t+1}^{\text {soep }}=\beta E_{t} R_{t+1} U_{T, t+1}^{p c}+\beta E_{t} R_{t+1} \mu_{t+1}^{p c} \Psi_{t+1}^{p c}$, so when the last term of (A.8) is positive (negative), the periphery coordinator values bond holdings more (less) than the SOE planners.

Periphery Coordinator vs. Decentralized agents: Consider a reallocation of resources by the coordinator starting from the optimal allocations in the decentralized equilibrium. This implies holding one more unit of bonds yields identical marginal costs to the decentralized agents and the periphery coordinator, $U_{T, t}^{d e}=U_{T, t}^{p c}$, but different marginal benefits. Because at the initial allocations, $\beta E_{t} R_{t+1} U_{T, t+1}^{d e}=\beta E_{t} R_{t+1} U_{T, t+1}^{p c}$, comparing (A.1) to (A.8) to see that the marginal benefits differ by the sum of two terms: $\beta E_{t} R_{t+1} \mu_{t+1}^{p c} \Psi_{t+1}^{p c}+\beta E_{t}\left[U_{T, t+1}^{p c}+\right.$ $\left.\mu_{t+1}^{p c} \Psi_{t+1}^{p c}\right] b_{t+1} \frac{\partial R_{t+1}}{\partial b_{t+1}}$. When the peripheral countries are saving $b_{t+1}>0$, the last term is negative and the sum may be positive or negative depending on the relative strength of the two terms, hence the periphery coordinator may value additional bond holdings more or less relative to the decentralized agents. On the other hand, when the peripheral countries are borrowing $b_{t+1}<0$, the sum of the two terms is always positive, so the periphery coordinator always values bond holdings more relative to the decentralized agents.

\section{A.5 Proof of Proposition 3}

Proof. We write the Euler equations under the three equilibria respectively below:

$$
\begin{gathered}
U_{T, t}^{d e}=\beta E_{t} R_{t+1} U_{T, t+1}^{d e}\left(1+\tau_{t}\right)+\mu_{t}^{d e} \\
U_{T, t}^{\text {seep }}=\beta E_{t} R_{t+1}\left[U_{T, t+1}^{\text {soep }}+\mu_{t+1}^{\text {soep }} \Psi_{t+1}^{\text {soep }}\right]+\mu_{t}^{\text {soep }}\left(1-\Psi_{t}^{\text {soep }}\right) \\
U_{T, t}^{p c}=\beta E_{t} R_{t+1}\left[U_{T, t+1}^{p c}+\mu_{t+1}^{p c} \Psi_{t+1}^{p c}\right]+\mu_{t}^{p c}\left(1-\Psi_{t}^{p c}\right)+\beta E_{t}\left[U_{T, t+1}^{p c}+\mu_{t+1}^{p c} \Psi_{t+1}^{p c}\right] b_{t+1} \frac{\partial R_{t+1}}{\partial b_{t+1}}
\end{gathered}
$$

By comparing the three Euler equations, it is straightforward to show that a tax on private agent's bond holdings:

$$
\tau_{t}^{\text {soep }}=E_{t} \mu_{t+1}^{\text {soep }} \Psi_{t+1}^{\text {soep }} / E_{t} U_{T, t+1}^{\text {soep }}-\mu_{t}^{\text {soep }} \Psi_{t}^{\text {soep }} / \beta E_{t} R_{t+1} U_{T, t+1}^{\text {soep }}
$$

restores the national regulator's equilibrium allocations, and a tax

$$
\begin{aligned}
\tau_{t}^{p c} & =E_{t} \mu_{t+1}^{p c} \Psi_{t+1}^{p c} / E_{t} U_{T, t+1}^{p c}-\left(\mu_{t}^{p c} \Psi_{t}^{p c}\right) /\left(\beta E_{t} R_{t+1} U_{T, t+1}^{p c}\right) \\
& +E_{t}\left[U_{T, t+1}^{p c}+\mu_{t+1}^{p c} \Psi_{t+1}^{p c}\right] b_{t+1} \frac{\partial R_{t+1}}{\partial b_{t+1}} /\left(E_{t} R_{t+1} U_{T, t+1}^{p c}\right)
\end{aligned}
$$

where $\partial R_{t+1} / \partial b_{t+1}$ is given by (A.5), implements the periphery coordinator's allocations when the proceeds are redistributed to the private agents in a lump-sum fashion. 


\section{B Solution Methods}

This section describes the global non-linear numerical methods that we use to solve the three equilibria in our paper. For all three equilibria, the state variables are the bond position for all the peripheral countries $b$, the current endowment realization $y$ (consists of tradable endowment $y_{T}$ and nontradable endowment $y_{N}$ ), and current financial condition realization $\kappa$. We discretize the bond position space into a 900-point evenly-spaced grid. We use the method described by Tauchen (1986) to discretize the tradable and nontradable endowment processes. We allow 4 realizations for both tradable and nontradable endowments, so there is a total of 16 endowment realizations. The processes for the endowment and financial condition are discussed in section 5.1.

B.1 Decentralized Agents' And SOE Planner's Problem We use Euler equation iteration to solve for the decision rules of the decentralized agents' and the representative SOE planner's problem. The solution method involves iterating on the recursive Euler equation until it converges and it is described in Coleman (1991) and Baxter (1991). It is then incorporated into models with occasionally binding constraints by Bianchi (2011) and we follow his algorithm closely to solve for the decentralized agents' and the representative SOE planner's problems. To solve the decentralized agents' problem, we need to solve for functions $\left\{b^{\prime}(b, y, \kappa), c_{T}(b, y, \kappa), c(b, y, \kappa), p(b, y, \kappa), \mu(b, y, \kappa)\right\}$ such that:

$$
\begin{aligned}
U_{T}(c(b, y, \kappa)) & =\beta R\left(b^{\prime}\right) E_{y^{\prime}, \kappa^{\prime} \mid y, \kappa} U_{T}\left(c\left(b^{\prime}, y^{\prime}, \kappa^{\prime}\right)\right)+\mu(b, y, \kappa) \\
c(b, y, \kappa) & =\left[\omega\left(c_{T}(b, y, \kappa)\right)^{-\eta}+(1-\omega)\left(y_{N}\right)^{-\eta}\right]^{-1 / \eta} \\
c_{T}(b, y, \kappa)+b^{\prime}(b, y, \kappa) & =y_{T}+R(b) b \\
-b^{\prime}(b, y, \kappa) & \leq \kappa\left(y_{T}+p(b, y, \kappa) y_{N}\right) \\
p(b, y, \kappa) & =\frac{1-\omega}{\omega}\left(\frac{c_{T}(b, y, \kappa)}{y_{N}}\right)^{1+\eta}
\end{aligned}
$$

where the world interest function $R(b)$ is given by (4.4). The algorithm to solve the decentralized agents' problem follows:

1. Discretize the state space and generate a grid according to the method described above. We use linear interpolation to interpolate over the bond position grid.

2. Make an initial guess of $\left\{b_{0}^{\prime}(b, y, \kappa), c_{T 0}(b, y, \kappa), c_{0}(b, y, \kappa), p_{0}(b, y, \kappa), \mu_{0}(b, y, \kappa)\right\}$ for each state $(b, y, \kappa)$.

3. Set $j=0$.

4. For a given $j$ and function $\left\{b_{j}^{\prime}(b, y, \kappa), c_{T, j}(b, y, \kappa), c_{j}(b, y, \kappa), p_{j}(b, y, \kappa), \mu_{j}(b, y, \kappa)\right\}$, we can solve for $\left\{b_{j+1}^{\prime}(b, y, \kappa), c_{T, j+1}(b, y, \kappa), c_{j+1}(b, y, \kappa), p_{j+1}(b, y, \kappa), \mu_{j+1}(b, y, \kappa)\right\}$ for a state $(b, y, \kappa)$ by 
(a) Assume the collateral constraint (B.4) is not binding. Set $\mu_{j+1}(b, y, \kappa)=0$ and solve for $b_{j+1}^{\prime}(b, y, \kappa), c_{T, j+1}(b, y, \kappa), c_{j+1}(b, y, \kappa)$ and $p_{j+1}(b, y, \kappa)$ using (B.1), (B.2), (B.3), (B.5) and a one-dimensional root finding algorithm.

(b) Use price function from the last step $p_{j}(b, y, \kappa)$, check if the collateral constraint (B.4) is satisfied. By using the last iteration's price function, we can avoid the problem of multiplicity in the root finding problem and it becomes innocuous when the price function converges. For robustness check, we start from different initial guesses and always get the same result.

(c) If the collateral constraint is satisfied, move to the next grid point.

(d) If the collateral constraint is not satisfied, set $b_{j+1}^{\prime}(b, y, \kappa)=-\kappa\left(y_{T}+p_{j}(b, y, \kappa) y_{N}\right)$ and then solve for $c_{T, j+1}(b, y, \kappa), c_{j+1}(b, y, \kappa), \mu_{j+1}(b, y, \kappa)$ and $p_{j+1}(b, y, \kappa)$ using (B.1) , (B.2), (B.3) and (B.5).

5. Check for convergence. If $\left|x_{j}(b, y, \kappa)-x_{j+1}(b, y, \kappa)\right|>\epsilon$ for any $(b, y, \kappa)$ and $x \in\left\{b^{\prime}, c_{T}, c, p, \mu\right\}$, then go back to step 3 with $j=j+1$. Otherwise, the iteration converges and we have found the equilibrium.

To solve for the representative SOE planner's problem, we use the same algorithm above. However, instead of using decentralized agents' Euler equation (B.1), we use the representative SOE planner's Euler equation:

$$
\begin{gathered}
U_{T}(c(b, y, \kappa))=\beta R\left(b^{\prime}\right) E_{y^{\prime}, \kappa^{\prime} \mid y, \kappa}\left[U_{T}\left(c\left(b^{\prime}, y^{\prime}, \kappa^{\prime}\right)\right)+\mu\left(b^{\prime}, y^{\prime}, \kappa^{\prime}\right) \Psi\left(b^{\prime}, y^{\prime}, \kappa^{\prime}\right)\right] \\
+\mu(b, y, \kappa)(1-\Psi(b, y, \kappa))
\end{gathered}
$$

where $\Psi(b, y, \kappa)=\kappa p(b, y, \kappa)(1+\eta)\left(y_{N} / c_{T}(b, y, \kappa)\right)$

B.2 Periphery COORDinAtor's Problem We use value function iteration to solve the periphery coordinator's problem. The periphery coordinator's problem can be written recursively as:

$$
\begin{aligned}
V(b, y, \kappa) & =\max _{b^{\prime}} u(c(b, y, \kappa))+\beta E\left(V\left(b^{\prime}, y^{\prime}, \kappa^{\prime}\right) \mid y, \kappa\right) \\
c_{T}(b, y, \kappa)+b^{\prime} & =y_{T}+\frac{b y_{2}^{*}}{\left(1+\beta^{*}\right) b+\beta^{*} y_{1}^{*}} \\
-b^{\prime} & \leq \kappa\left(y_{T}+\frac{1-\omega}{\omega}\left(\frac{c_{T}(b, y, \kappa)}{y_{N, t}}\right)^{1+\eta} y_{N}\right) \\
c(b, y, \kappa) & =\left[\omega\left(c_{T}(b, y, \kappa)\right)^{-\eta}+(1-\omega)\left(y_{N}\right)^{-\eta}\right]^{-1 / \eta}
\end{aligned}
$$

We use cubic splines to approximate the value function of the periphery coordinator $V(b, y, \kappa)$ and solve the maximization problem using sequential quadratic programming algorithm from the NLopt package in Fortran. We then apply the standard value function iteration method to solve for the decision rules of the periphery coordinator under each state $(b, y, \kappa)$. 


\section{Decomposition Of SHOcks}

In our baseline model, the peripheral countries are subject to three shocks: the financial shock, the nontradable endowment shock, and the tradable endowment shock. In this section we investigate the role and the relative contribution of each shock to the model statistics. Table 4 shows the average NFA position, the probability of crisis, and the welfare gains when we shut down each shock in turn. Table 4 shows that, in general, less uncertainty reduces the probability of crisis. As a result, the peripheral countries lower their average NFA position since their need for precautionary savings is weakened.

Among the three shocks, the tradable endowment shock contributes the most to generate the model statistics. When the peripheral countries' tradable endowment is fixed at its mean, the probability of crisis becomes almost zero. In addition, the precautionary saving motive is greatly weakened and the average NFA position plunges to $0.74 \%$ of tradable GDP. Since there is only a negligible probability that the peripheral countries will experience a financial crisis, national regulation improves welfare marginally at $1.82 \times 10^{-6} \%$ of permanent consumption. In this case, there is little room for the periphery coordinator to exert market power when borrowing and saving in the international financial market due to the low average NFA position. As a result, the welfare gain in the periphery countries and the welfare loss in the core country are significantly less than that in the baseline case.

Nontradable goods shock plays a qualitatively similar role to the tradable goods shock, only quantitatively less important. We can see from the third column that the probability of crisis and the average NFA are lower in all three equilibra. In addition, the welfare gain is lower than the baseline case. Lastly, the financial shock is the least significant contributor to the model dynamics. However, even though the probability of crisis is lowered, the SOE planner can still yield a higher welfare gain than in the baseline case when the financial shock is absent. The absence of the financial shock induces the peripheral countries to save less than the baseline case and thus they have smaller welfare losses due to the low rate of return resulting from excessive savings.

Table 4: Decomposition of Shocks

\begin{tabular}{|c|c|c|c|c|c|}
\hline & & Baseline & $\begin{array}{l}\text { No Financial } \\
\text { Shock }\end{array}$ & $\begin{array}{l}\text { No Nontradable } \\
\text { Goods shock }\end{array}$ & $\begin{array}{l}\text { No Tradable } \\
\text { Goods Shock }\end{array}$ \\
\hline \multirow{2}{*}{$\begin{array}{c}\text { Decentralized } \\
\text { Agents }\end{array}$} & Average NFA Position & $27.97 \%$ & $25.69 \%$ & $15.10 \%$ & $0.74 \%$ \\
\hline & Probability of Crisis & $0.39 \%$ & $0.23 \%$ & $0.29 \%$ & $7.77 \times 10^{-4 \%}$ \\
\hline \multirow{4}{*}{$\begin{array}{c}\text { SOE } \\
\text { Planners }\end{array}$} & Average NFA Position & $29.17 \%$ & $26.51 \%$ & $16.00 \%$ & $0.74 \%$ \\
\hline & Probability of Crisis & $0.26 \%$ & $0.16 \%$ & $0.19 \%$ & $5.55 \times 10^{-4 \%}$ \\
\hline & Periphery Welfare Gain & $0.001 \%$ & $0.0026 \%$ & $7.28 \times 10^{-4} \%$ & $1.82 \times 10^{-6 \%}$ \\
\hline & Core Welfare Gain & $6.62 \times 10^{-6 \%}$ & $9.51 \times 10^{-7 \%}$ & $-3.33 \times 10^{-8} \%$ & $-1.75 \times 10^{-8 \%}$ \\
\hline \multirow{4}{*}{$\begin{array}{l}\text { Periphery } \\
\text { Coordinator }\end{array}$} & Average NFA Position & $15.60 \%$ & $13.56 \%$ & $7.51 \%$ & $0.55 \%$ \\
\hline & Probability of Crisis & $0.23 \%$ & $0.13 \%$ & $0.12 \%$ & $0 \%$ \\
\hline & Periphery Welfare Gain & $0.021 \%$ & $0.021 \%$ & $0.011 \%$ & $0.0023 \%$ \\
\hline & Core Welfare Gain & $-4.26 \times 10^{-4 \%}$ & $-4.15 \times 10^{-4 \%}$ & $-2.14 \times 10^{-4 \%}$ & $-3.83 \times 10^{-5 \%}$ \\
\hline
\end{tabular}

